\title{
Nanoparticle-induced inflammation and fibrosis in ex vivo murine precision-cut liver slices and effects of nanoparticle exposure conditions
}

\author{
Roberta Bartucci ${ }^{1,2,3} \cdot$ Alex Z. van der Meer $^{1} \cdot$ Ykelien L. Boersma $^{3} \cdot$ Peter Olinga $^{2} \cdot$ Anna Salvati $^{1}$ (D)
}

Received: 16 December 2020 / Accepted: 21 January 2021 / Published online: 8 February 2021

(c) The Author(s) 2021

\begin{abstract}
Chronic exposure and accumulation of persistent nanomaterials by cells have led to safety concerns on potential long-term effects induced by nanoparticles, including chronic inflammation and fibrosis. With this in mind, we used murine precisioncut liver tissue slices to test potential induction of inflammation and onset of fibrosis upon $72 \mathrm{~h}$ exposure to different nanomaterials $(0-200 \mu \mathrm{g} / \mathrm{ml})$. Tissue slices were chosen as an advanced ex vivo 3D model to better resemble the complexity of the in vivo tissue environment, with a focus on the liver where most nanomaterials accumulate. Effects on the onset of fibrosis and inflammation were investigated, with particular care in optimizing nanoparticle exposure conditions to tissue. Thus, we compared the effects induced on slices exposed to nanoparticles in the presence of excess free proteins (in situ), or after corona isolation. Slices exposed to daily-refreshed nanoparticle dispersions were used to test additional effects due to ageing of the dispersions. Exposure to amino-modified polystyrene nanoparticles in serum-free conditions led to strong inflammation, with stronger effects with daily-refreshed dispersions. Instead, no inflammation was observed when slices were exposed to the same nanoparticles in medium supplemented with serum to allow corona formation. Similarly, no clear signs of inflammation nor of onset of fibrosis were detected after exposure to silica, titania or carboxylated polystyrene in all conditions tested. Overall, these results show that liver slices can be used to test nanoparticle-induced inflammation in real tissue, and that the exposure conditions and ageing of the dispersions can strongly affect tissue responses to nanoparticles.
\end{abstract}

Keywords Liver slices $\cdot$ Ex vivo $\cdot$ Corona-coated nanoparticles $\cdot$ Aging $\cdot$ Inflammation $\cdot$ Fibrosis

\section{Introduction}

Long-term in vivo biodistribution studies have suggested that nanomaterials may accumulate and persist at cellular level, giving rise to the question on the potential induction of chronic effects (Nel 2006; Krug 2014; Armstead and Li 2016; Devasena 2017; Landsiedel et al. 2017). Nanomaterials that are not excreted by renal or hepatobiliary elimination have been found to remain in the blood circulation and accumulate over time, mainly in the liver (Poon et al. 2019). The liver can sequester around 30-99\% of nanomaterials from the systemic circulation, and long-term studies have shown that nanomaterials can be retained in this organ for months or even years (Zhang et al. 2016; Tsoi et al. 2016). Accumulation over time of nanomaterials might result in oxidative stress and DNA damage at cell level, ultimately leading to inflammation and cell death in the tissue (Rim et al. 2013; Ajdary et al. 2018). All this can cause lifelong pathological conditions, such as fibrosis (Hong and Zhang 
2016; Yu et al. 2017; Lee et al. 2018). Fibrosis is characterized by the excessive production of extracellular matrix proteins by activated fibroblasts. These cells can be activated by transforming growth factor beta- 1 (TGF- $\beta 1$ ) and other inflammatory cytokines released by immune cells, including Kupffer cells, the resident liver macrophages (Zeisberg and Kalluri 2013). Indeed, nanoparticle distribution studies have shown that the mononuclear phagocyte system plays a key role in the clearance of nanomaterials, and within the liver, the Kupffer cells accumulate high amounts of nanoparticles (Ogawara et al. 1999; Sadauskas et al. 2007; De Jong et al. 2008; Dragoni et al. 2012; Gustafson et al. 2015). Additionally, some in vivo studies have already reported that some nanomaterials, such as $\mathrm{TiO}_{2}$ and $\mathrm{SiO}_{2}$, can induce fibrosis (Chen et al. 2009; Hong and Zhang 2016; Yu et al. 2017).

Within this context, in this work we aimed to test potential induction of inflammation and fibrosis in the liver upon long-term exposure to nanomaterials. In vivo models are generally considered and are still used as the gold standard to conduct chronic nanotoxicity studies (Arts et al. 2007; Park and Park 2009; Xie et al. 2010; Chan et al. 2017). However, recent efforts have been focused on the development of in vitro models (including for the liver) that could allow chronic exposure for screening of potential long-term effects induced by nanoparticles (Godoy et al. 2013; Wick et al. 2015; Usta et al. 2015; Starokozhko and Groothuis 2018). Therefore, the lifetime of cell cultures, co-cultures and 3D-organoids has been optimized to be extended up to weeks, as well as to allow the use of lower doses, to capture subtle effects induced by nanoparticles in chronic settings (Thurnherr et al. 2011; Alépée 2014; Drasler et al. 2017). However, resembling the complexity and architecture of real liver tissue remains a challenge (Materne et al. 2013; Starokozhko and Groothuis 2017, 2018). In this regard, precision-cut tissue slices are well established as a promising alternative model that allows to maintain the original architecture and complexity of real tissue (Parrish et al. 1995; Graaf et al. 2007; de Graaf et al. 2010). In particular, liver slices represent a very interesting ex vivo model for nanosafety studies, considering the key role that the liver has in relation to the fate of nanomaterials (Dragoni et al. 2012; Olinga and Schuppan 2013). Additionally, liver tissue slices can also be used as a model for the onset of fibrosis (Olinga et al. 2001; Westra et al. 2014a, 2016), since during culture they spontaneously overexpress early-fibrosis markers, e.g., heat shock protein 47 and pro-collagen 1, resembling the onset of the disease. Furthermore, when stimulated with profibrotic (TGF- $\beta 1$ or PDGF- $\beta$ ) and pro-inflammatory (LPS) factors, the diseased status appears exacerbated and stronger inflammatory responses are observed (Westra et al. 2013, 2014b).

Because of these reasons, and to test nanomaterials directly on full tissue, in this work we have selected liver slices as an advanced 3D ex vivo model to test the potential induction of inflammation and fibrosis in liver tissue upon exposure to nanomaterials. Nanoparticles were exposed to mouse liver slices for $72 \mathrm{~h}$ (currently set as the longest culture time with preserved tissue functions) and changes in the expression levels of a panel of markers of inflammation were monitored. The expression of fibrosis markers was also quantified, combined with collagen staining of tissue sections. Even though the exposure time was limited to $72 \mathrm{~h}$, given the spontaneous onset of fibrosis in the tissue slices during culture (Westra et al. 2014b, 2016), tissue slices allowed us to test eventual differences upon exposure to nanoparticles, as a sign of nanoparticle-induced effects on the onset of fibrotic responses.

In doing so, we paid particular attention to additional effects of nanoparticle exposure conditions on the outcomes observed at tissue level. This is a key aspect to be considered, because the exposure conditions can strongly affect nanoparticle interactions with cells and tissue. When nanoparticles are tested, a representative biological fluid has to be included, since, once applied in vivo, proteins and other biomolecules from the environment in which nanoparticles are applied adsorb on their surface, forming the so-called protein corona. This layer completely alters the behavior of nanomaterials at cell and organism levels (Lesniak et al. 2012; Monopoli et al. 2012; Wang et al. 2013b; Duan et al. 2015). Thus, for nanoparticle exposure to liver, a source of serum proteins must be included to avoid artifacts. With this in mind, as a first approximation, in the current study nanoparticles were added to the tissue slices in medium supplemented with 5\% fetal bovine serum. Additionally, to differentiate potential effects on the tissue due to the presence of serum, liver slices were exposed both to nanoparticles with the excess free proteins left in solution (in situ) or to isolated corona-coated nanoparticles in serum free conditions (Jasbi and Dorranian 2016; Lu et al. 2017). Slices exposed to nanoparticle dispersions refreshed daily were also included for comparison. It is in fact known that dispersions in biological fluids can age, and not only the corona composition may change over time (for instance due to cellular proteins excreted by cells) (Casals et al. 2010; Lundqvist et al. 2011; Lesniak et al. 2012; Hadjidemetriou and Kostarelos 2017; Giau et al. 2019), but also stability may be impaired, and agglomeration and/or settling of nanoparticles could complicate the outcomes (Cho et al. 2011; Lesniak et al. 2012; Kastl et al. 2013; Feliu et al. 2017; Böhmert et al. 2018).

Overall, using tissue slices we have monitored activation of inflammation and possible appearance of fibrosis on full liver tissue upon exposure to nanomaterials, and tested explicitly how exposure conditions and ageing of the nanoparticle dispersions in biological conditions affect the outcomes. 


\section{Materials and methods}

\section{Animals}

Livers were extracted from C57BL/6J mice aged 6-10 weeks, both male and female. Mice had access to food and water ad libitum and were kept under a 12-h day/ night cycle (Central Laboratory Animal Facility, UMCG, Groningen). Animals were allowed to acclimatize for at least 1 week before starting the experiments. Mice were sedated with $5 \%$ isoflurane in $\mathrm{O}_{2}$ and livers were extracted in a terminal procedure. The organ was stored in University of Wisconsin solution (UW) (DuPont Critical Care) on ice until further use. All experiments were approved by the Institutional Animal Care and Use Committee of the University of Groningen (Approval number: Dec 6416AA-001).

\section{Liver slice preparation}

Liver slices were prepared as described earlier by De Graaf et al. (2010). Briefly, $5 \mathrm{~mm}$ diameter tissue cores were prepared using a $5 \mathrm{~mm}$ disposable biopsy puncher (Integra Miltex) and kept in ice cold UW organ preservation solution. A Krumdieck Tissue Slicer MD6000 (Alabama R\&D) was filled with ice-cold Krebs-Henseleit buffer supplemented with $25 \mathrm{mM}$ D-glucose (Merck), $25 \mathrm{mM}$ $\mathrm{NaHCO}_{3}$ (Merck), $10 \mathrm{mM}$ HEPES (MP Biomedicals), and saturated with a mixture of $95 \%$ oxygen and $5 \% \mathrm{CO}_{2}$. Tissue slices were cut with a thickness of 250-350 $\mu \mathrm{m}$, and a wet weight of roughly $5 \mathrm{mg}$. After the cutting procedure, liver slices were transferred to ice-cold UW until further use.

\section{Pre-incubation}

Prior to experiments, liver slices were transferred to a petri dish containing William's Medium E + GlutaMAX (WME, with L-glutamine, Invitrogen) medium supplemented with $25 \mathrm{mM}$ D-glucose and $50 \mu \mathrm{g} / \mathrm{ml}$ gentamycin (Invitrogen) to remove the UW solution. Next, liver slices were transferred to individual wells in a 12-well plate filled with $1.3 \mathrm{ml}$ pre-warmed $\left(37^{\circ} \mathrm{C}\right)$ serum-free WME medium or WME medium supplemented with $5 \%$ v/v Fetal Bovine Serum (FBS, Gibco from TermoFisher Scientific), saturated with $80 \% \mathrm{O}_{2} / 5 \% \mathrm{CO}_{2}$. Finally, the slices were maintained in an incubator (Panasonic) at $37{ }^{\circ} \mathrm{C}$ saturated with $80 \% \mathrm{O}_{2} / 5 \% \mathrm{CO}_{2}$ and under gentle shaking (90 rpm) for $3 \mathrm{~h}$, prior to exposure to the nanoparticles. The $3 \mathrm{~h}$ pre-incubation allows the tissue to restore its function and decreases the presence of residual cell debris present on the edge of the slices after the cutting procedure, which could affect the subsequent exposure to nanoparticles (Bartucci et al. 2020).

\section{Preparation of nanoparticle dispersion and isolation of corona-coated $\mathrm{SiO}_{2}$ and PS-COOH nanoparticles}

Far-red labelled 40 nm carboxylated polystyrene nanoparticles (FluoSpheres, PS-COOH, maximum excitation at $660 \mathrm{~nm}$ and emission at $680 \mathrm{~nm}$ ) were purchased from Thermo Fisher Scientific; unlabeled $50 \mathrm{~nm}$ amino-modified polystyrene nanoparticles $\left(\mathrm{PS}-\mathrm{NH}_{2}\right.$ ) were purchased from Bangs Laboratories; red labelled $50 \mathrm{~nm}$ plain silica dioxide nanoparticles $\left(\mathrm{SiO}_{2}\right.$, maximum excitation at $569 \mathrm{~nm}$ and emission at $585 \mathrm{~nm}$ ) were purchased from Kisker Biotech; unlabeled $8 \mathrm{~nm}$ titanium dioxide anatase nanoparticles $\left(\mathrm{TiO}_{2}\right)$ were purchased from PlasmaChem.

Nanoparticle dispersions were prepared during tissue slice pre-incubation and used immediately after preparation. After vortexing the nanoparticle stock for $3 \mathrm{~min}$, dispersions at different concentrations were prepared by serial dilutions. Nanoparticle dispersions were prepared in serum-free WME (SF-WME) or in WME + 5\% FBS (in situ). Corona-coated particles were isolated as follows, and added to tissue in serum-free medium. To prepare coronacoated PS-COOH and $\mathrm{SiO}_{2}, 200 \mu \mathrm{g} / \mathrm{ml}$ nanoparticles were first dispersed in high serum content (40\% FBS, roughly corresponding to $16 \mathrm{mg} / \mathrm{ml}$ proteins) in Dulbecco's phosphate buffered solution (DPBS, ThermoFisher Scientific). This dispersion was incubated for at least $1 \mathrm{~h}$ in the dark at $37^{\circ} \mathrm{C}$ while gently shaking at $250 \mathrm{rpm}$. Afterwards, the dispersion was centrifuged for $1 \mathrm{~h}$ at $20.000 \mathrm{rcf}$ for PS$\mathrm{COOH}$ or $16.000 \mathrm{rcf}$ for $\mathrm{SiO}_{2}$ to pellet the corona-coated nanoparticles. The supernatant containing excess free proteins was discarded immediately and the pelleted coronananoparticle complexes were carefully resuspended in $200 \mu \mathrm{l}$ DPBS by pipetting up and down until no pellet was visible. The dispersion was then centrifuged at $16.000 \mathrm{rcf}$ for $30 \mathrm{~s}$ to check if the pellet was dispersed sufficiently. If pellet formation was observed, the dispersion was pipetted up and down again and centrifugation at $16.000 \mathrm{rcf}$ for $30 \mathrm{~s}$ was repeated. If no pelleting was observed, the corona-nanoparticle complexes were considered sufficiently dispersed [as also tested by dynamic light scattering (DLS) - as described below]. Serum-free medium was added to reach the highest final nanoparticle concentration of $100 \mu \mathrm{g} / \mathrm{ml}$. From here, samples at different nanoparticle concentration, down to $25 \mu \mathrm{g} / \mathrm{ml}$ were prepared by serial dilution. To verify that homogenous corona-nanoparticle dispersions were obtained, DLS was used to determine the 
size distribution of the samples obtained in each independent experiment.

\section{DLS measurement}

The nanoparticle dispersions in relevant buffers were characterized by dynamic light scattering (DLS) using a Malvern Zetasizer Nano ZS (Malvern Instruments Ltd). Briefly, $100 \mu \mathrm{g} / \mathrm{ml} \mathrm{PS}-\mathrm{COOH}, \mathrm{PS}-\mathrm{NH}_{2}, \mathrm{SiO}_{2}$ and $\mathrm{TiO}_{2}$ nanoparticles in WME medium supplemented with 5\% v/v FBS were prepared by dilution of the nanoparticle stocks and measured immediately after dispersion. In addition, $100 \mu \mathrm{g} / \mathrm{ml}$ coronacoated nanoparticle dispersions in serum-free WME prepared as described above were also characterized by DLS. The results are the average of three separate measurements, each containing 10 runs of $10 \mathrm{~s}$.

\section{Exposure to nanoparticles}

After a $3 \mathrm{~h}$ pre-incubation, liver slices were exposed to nanoparticles by transferring them to pre-warmed $\left(37^{\circ} \mathrm{C}\right)$ and pre-saturated $\left(80 \% \quad \mathrm{O}_{2} / 5 \% \quad \mathrm{CO}_{2}\right)$ wells containing nanoparticle dispersions at different doses in serum-free WME medium or WME medium supplemented with 5\% $\mathrm{v} / \mathrm{v}$ FBS, prepared as described above. Then, the liver slices were maintained in culture up to $72 \mathrm{~h}$ exposure in the same medium. To compare results in slices exposed to daily refreshed medium, for some samples the medium and/or the freshly prepared nanoparticle dispersion or corona-isolated nanoparticles were replaced every $24 \mathrm{~h}$.

\section{Viability of liver slices}

The viability of liver slices was determined based on adenosine triphosphate (ATP) content normalized by total protein content. The ATP content of the slices was determined using an ATP bioluminescence assay (Sigma Aldrich). The amount of light produced correlates directly to the amount of ATP present, which allows calculation of ATP content using a calibration curve. After exposure, slices were snap-frozen in sonification solution (SONOP) with $\mathrm{pH}$ 10.9. SONOP is constituted by $2 \mathrm{mM}$ EDTA and $70 \% \mathrm{v} / \mathrm{v}$ ethanol. Then, the slices were thawed on ice and homogenized for $45 \mathrm{~s}$ using a mini-beadbeater-24 (Biospec). An ATP calibration curve was prepared from ATP standards and $50 \mu \mathrm{l}$ of each sample at different concentration were transferred in duplicate in a black 96-well plate (Costar). Next, the homogenized samples were centrifuged at $16,100 \mathrm{rcf}$ for $5 \mathrm{~min}$ at $4{ }^{\circ} \mathrm{C}$. Part of the supernatant was transferred to new safe-lock Eppendorf cups and the cups with the pellet were dried overnight at $37^{\circ} \mathrm{C}$ for determination of the protein content. Next, $5 \mu \mathrm{l}$ of the transferred supernatant was pipetted in duplicate in a 96-well plate and diluted with $45 \mu \mathrm{l} 100 \mathrm{mM}$ Tris- $\mathrm{HCl}(\mathrm{pH}$ 7.6-8.0)
(VWR International Prolabo), with 2 mM EDTA. Finally, $50 \mu \mathrm{l}$ of the luciferase/luciferin mix was added to each well and luminescence (relative fluorescence units, RFU) was measured immediately and after $5 \mathrm{~min}$ using a luminescence microplate reader (LumiCount BL10000, Packard). Calculations were performed using the RFU at $5 \mathrm{~min}$.

The total protein content of the samples was determined using a colorimetric protein assay (DC protein assay, BioRad). Two hundred $\mu$ l of $5 \mathrm{M} \mathrm{NaOH}$ was added to the dried pellets in Eppendorf cups from the ATP assay and incubated for $30 \mathrm{~min}$ in a water bath at $37^{\circ} \mathrm{C}$ while gently shaking at $100 \mathrm{rpm}$. Meanwhile, a protein calibration curve was made from bovine serum albumin (BSA, ICN Biomedicals Inc.) in $1 \mathrm{M} \mathrm{NaOH}$. After incubation for $30 \mathrm{~min}$, the samples were diluted to $1 \mathrm{M} \mathrm{NaOH}$ by adding $800 \mu \mathrm{l}$ ultrapure water and then homogenized for $45 \mathrm{~s}$ using a mini-beadbeater. Five $\mu \mathrm{l}$ of each standard dilution for the calibration curve and of each sample were pipetted in duplicate in a clear, flat bottom 96-well plate. A multichannel pipet was used to add $25 \mu \mathrm{l}$ of reagent A and $200 \mu \mathrm{l}$ reagent B to all filled wells. The plate was stored in the dark for $15 \mathrm{~min}$ and finally the absorbance at $650 \mathrm{~nm}$ was measured using a microplate reader (THERMOmax microplate reader, Molecular Devices).

Finally, for each slice the viability was calculated by normalizing the ATP value (pmol) by the amount of total protein $(\mu \mathrm{g})$. For each condition three slices were used, and the average and standard error of the mean were calculated. Supplementary Figures S2, S5, S8 and S12 show the results of the three independent experiments, together with their mean (indicated with a line) and standard error of the mean.

\section{mRNA extraction, CDNA synthesis and qRT-PCR}

For mRNA extraction, for each sample three slices were pooled together. Samples for mRNA expression analysis were transferred to $1.5 \mathrm{ml}$ cups containing glass beads and a homogenization solution supplemented with 1-thioglycerol from a Maxwell 16 LEV simply RNA purification kit (Promega). Next, the samples were homogenized using a minibeadbeater and homogenates were heated to $70{ }^{\circ} \mathrm{C}$ for $2 \mathrm{~min}$. A Maxwell 16 Instrument set to the simplyRNA protocol was used to isolate RNA from the processed samples into nucleasefree water. Afterwards, the RNA concentration of each sample was determined using a Nanodrop ND-1000 spectrophotometer (Thermo Fisher Scientific, the Netherlands). Subsequently, the volume of RNA solution needed to obtain $1.6 \mu \mathrm{g}$ of isolated RNA was calculated based on the RNA concentration and nuclease-free water was added to obtain a total volume of $10 \mu \mathrm{l}$. If $1.6 \mu \mathrm{g}$ of RNA could not be obtained with a volume of $<10 \mu$ l RNA solution, $10 \mu$ l of RNA was used (without further dilution) and the difference in total amount of RNA was adjusted for after cDNA synthesis. After preparation of the RNA, a cDNA synthesis reaction mix was made using 
an M-MLV reverse transcriptase kit (Promega). A volume of $8.5 \mu \mathrm{l}$ reaction mix was added to each sample to a total volume of $18.5 \mu$, then samples were vortexed and centrifuged for $1 \mathrm{~min}$ to remove any bubbles. Next, the samples were placed in an Eppendorf Mastercycler Gradient Thermal Cycler and heated as follows to reverse transcribe the RNA to cDNA: $20{ }^{\circ} \mathrm{C}$ for $10 \mathrm{~min}, 42{ }^{\circ} \mathrm{C}$ for $30 \mathrm{~min}, 20^{\circ} \mathrm{C}$ for $12 \mathrm{~min}, 99^{\circ} \mathrm{C}$ for $5 \mathrm{~min}$ and $20^{\circ} \mathrm{C}$ for $5 \mathrm{~min}$.

An amount of $1.6 \mu \mathrm{g}$ cDNA in $18.5 \mu \mathrm{l}$ water was synthesized, which was then diluted to $100 \mathrm{ng} / \mu \mathrm{l}$ in nuclease-free water. For each gene, the cDNA of each sample was pipetted in triplicate into a 384-Well Reaction Plate (MicroAmp, Applied Biosystems). Real-time quantitative polymerase chain reaction (RT-qPCR) was used to quantify the mRNA expression using the primers described in Table 1 and a SYBR green Low-ROX Kit (SensiMix, Bioline Reagents Limited). The primers were tested for efficiency and all had an efficiency between 90 and 105\%. A Quantstudio 7 flex Real-Time PCR System (Thermo Fisher Scientific) was used to run RT-qPCR with a hold stage of $10 \mathrm{~min}$ at $95^{\circ} \mathrm{C}$, a PCR stage of 40 cycles of $15 \mathrm{~s}$ at $95^{\circ} \mathrm{C}$ $\left(1.6{ }^{\circ} \mathrm{C} / \mathrm{s}\right)$ and $25 \mathrm{~s}$ at $65{ }^{\circ} \mathrm{C}\left(1.6^{\circ} \mathrm{C} / \mathrm{s}\right)$. A continuous melt curve stage was included with $15 \mathrm{~s}$ at $95^{\circ} \mathrm{C}\left(1.6^{\circ} \mathrm{C} / \mathrm{s}\right), 1 \mathrm{~min}$ at $65^{\circ} \mathrm{C}\left(1.6{ }^{\circ} \mathrm{C} / \mathrm{s}\right)$, and another $15 \mathrm{~s}$ at $95^{\circ} \mathrm{C}\left(0.05^{\circ} \mathrm{C} / \mathrm{s}\right.$, dissociation phase). Data was extracted using Quantstudio RealTime PCR software (version 1.3). Finally, the mRNA expression was calculated with the $2^{-\Delta \Delta C t}$ method, with $\beta$-actin used as a reference gene, to obtain relative fold induction values as follows:

$\Delta C t=C t_{\mathrm{gene}}-C t_{\beta \text {-actin }}$
$\Delta \Delta C t=\Delta C t_{\text {treated }}-\Delta C t_{\text {untreated }}$

Fold induction $=2^{-\Delta \Delta C t}$

\section{Paraffin sections of liver slices}

For paraffin embedding, slices were fixed in $4 \%$ formaldehyde in PBS for $24 \mathrm{~h}$ at $4{ }^{\circ} \mathrm{C}$ and stored in $70 \%$ ethanol at $4{ }^{\circ} \mathrm{C}$ until analysis. After dehydration in alcohol and xylene, the slices were embedded in paraffin and $4 \mu \mathrm{m}$ sections were cut perpendicular to the surface of the slice using a Leica Reichert-Jung 2040 Autocut Microtome. The sections were deparaffinated and incubated overnight in a $0.1 \mathrm{M}$ Tris- $\mathrm{HCl}$ buffer ( $\mathrm{pH} 9.0$ room temperature) at $80{ }^{\circ} \mathrm{C}$ for antigen retrieval.

\section{Collagen 1 immunostaining}

After antigen retrieval, the sections were washed in $1 \times \mathrm{PBS}$ (phosphate buffered saline, $\mathrm{pH} 7$ ) and circled using a DAKO pen (ImmEdge, Vector Laboratories inc.). A droplet of a 1:400 dilution of goat anti-type I collagen antibody (IgG, unlabeled, Southern Biotech) was added to the sections and incubated for $1 \mathrm{~h}$ at room temperature. Next, endogenous peroxidases were inhibited by incubating the sections in $0.1 \% \mathrm{H}_{2} \mathrm{O}_{2}$ in methanol for $20 \mathrm{~min}$. The sections were washed in $1 \times \mathrm{PBS}$, then incubated for $30 \mathrm{~min}$ with a 1:100 dilution of secondary antibody (rabbit-anti-goat IgG $(\mathrm{H}+\mathrm{L})$, Mouse/Rat/Human ads-horse radish peroxidase
Table 1 Primers used for qRTPCR

\begin{tabular}{|c|c|c|c|}
\hline Gene coding for & Name & & Sequence \\
\hline \multirow[t]{2}{*}{$\beta$-Actin } & \multirow[t]{2}{*}{$b$-Actin } & $F w$ & 5'-ATCGTGCGTGACATCAAAGA \\
\hline & & $R v$ & 5'-ATGCCACAGGATTCCATACC \\
\hline \multirow[t]{2}{*}{ Procollagen type $1 \alpha 1$} & \multirow[t]{2}{*}{ pCOLla1 } & $F w$ & 5'-TGACTGGAAGAGCGGAGAGT \\
\hline & & $R v$ & 5'-ATCCATCGGTCATGCTCTCT \\
\hline \multirow[t]{2}{*}{ Collagen type $1 \alpha 1$} & \multirow[t]{2}{*}{ COLlal } & $F w$ & 5'-TGACTGGAAGAGCGGAGAGT \\
\hline & & $R v$ & 5'-ATCCATCGGTCATGCTCTCT \\
\hline \multirow[t]{2}{*}{ Heat shock protein 47} & \multirow[t]{2}{*}{$H S P-47$} & $F w$ & 5'-AGGTCACCAAGGATGTGGAG \\
\hline & & $R v$ & 5'-CAGCTTCTCCTTCTCGTCGT \\
\hline \multirow[t]{2}{*}{$\alpha$ Smooth muscle actin } & \multirow[t]{2}{*}{$a-S M A$} & $F w$ & 5'-ACTACTGCCGAGCGTGAGAT \\
\hline & & $R v$ & 5'-CCAATGAAAGATGGCTGGAA \\
\hline \multirow[t]{2}{*}{ Interleukin $1 \beta$} & \multirow[t]{2}{*}{$I L-1 b$} & $F w$ & 5'-GCACTACAGGCTCCGAGATGAAC \\
\hline & & $R v$ & 5'-TTGTCGTTGCTTGGTTCTCCTTGT \\
\hline \multirow[t]{2}{*}{ Interleukin 4} & \multirow[t]{2}{*}{$I L-4$} & $F w$ & 5'-GTCTGCATCAAGACGCCATG \\
\hline & & $R v$ & 5'-CGTTGCTGTGAGGACGTTTG \\
\hline \multirow[t]{2}{*}{ Interleukin 6} & \multirow[t]{2}{*}{$I L-6$} & $F w$ & 5'-TGATGCTGGTGACAACCACGGC \\
\hline & & $R v$ & 5'-TAAGCCTCCGACTTGTGAAGTGGTA \\
\hline \multirow[t]{2}{*}{ Interleukin 10} & \multirow[t]{2}{*}{$I L-10$} & $F w$ & 5'-CCCAAGTAACCCTTAAAGTCCTGC \\
\hline & & $R v$ & 5'-ATAACTGCACССАСТТСССАGTC \\
\hline
\end{tabular}


(HRP) (Southern Biotech) in $1 \times$ PBS with $5 \%$ normal mouse serum (NMS), and washed again. After a 30-min incubation with a 1:100 dilution of tertiary antibody [goat-anti-rabbit $\mathrm{IgG}, \mathrm{IgG}(\mathrm{H}+\mathrm{L})-\mathrm{HRP}$, Southern Biotech] in $1 \times \mathrm{PBS}$ with $5 \%$ NMS, the sections were washed and incubated for $5 \mathrm{~min}$ with a Novared reaction mixture (ImmPACT, NovaRED peroxidase substrate kit for laboratory use, Vector Laboratories). The sections were incubated in hematoxylin for $1 \mathrm{~min}$, flushed with tap water for $5 \mathrm{~min}$, and dehydrated in three washes with $100 \%$ ethanol. Finally, the dehydrated sections were mounted using DePex (SERVA Electrophoresis $\mathrm{GmbH})$. Pictures of the stained sections were taken using an Olympus BX41 Microscope and Hamamatsu NanoZoomer digital slide scanner.

\section{Picro-Sirius Red staining}

The presence of both collagen type I and III fibers was shown using a histochemical Picro-Sirius Red staining. Similar to the collagen type I staining, slices in paraffin blocks were cut in $4 \mu \mathrm{m}$ sections and placed on glass slides (StarFrost, Waldemar Knittel glass). The sections were deparaffinated, incubated in hematoxylin for $30 \mathrm{~s}$, flushed with tap water for $5 \mathrm{~min}$, and then incubated for $1 \mathrm{~h}$ in an aqueous, saturated picric acid solution with $0.1 \mathrm{mg} / \mathrm{ml}$ Sirius Red (Sirius red, SCHMIDT GMBH \& CO.). Afterwards, the sections were washed in two changes of acid water; $0.5 \%$ acetic acid (glacial, $100 \%$, anhydrous, Sigma Aldrich) in ultrapure water and dehydrated in three changes of $100 \%$ ethanol. Finally, the sections were mounted using DePex and pictures were taken using Olympus BX41 Microscope.

\section{Statistics}

All experiments were carried out in biological triplicate or more ( $\geq 3$ animals) and each experiment included three replicate slices per condition. The results of each independent experiment are shown, together with an horizontal line for their mean and vertical lines for the standard error of the mean (SEM). The qRT-PCR results are shown as fold induction of $2^{-\Delta \Delta C t}$ over the control, but Kruskal-Wallis statistic followed by Dunnett's multiple comparisons test were performed on $\Delta C t$ values using GraphPad 5.0.

\section{Results}

\section{Response of the liver slices to different culture conditions}

Murine liver slices were prepared as previously described and exposed to a panel of nanomaterials for up to $72 \mathrm{~h}$ (de Graaf et al. 2010; Westra et al. 2014b). Precision-cut liver slices cultured for more than $48 \mathrm{~h}$ have been shown to spontaneously develop fibrosis (Westra et al. 2014b; Pham et al. 2015). Standard markers used to follow fibrogenesis and the development of fibrosis are upregulated at gene level over time. These include for instance heat shock protein-47 (Hsp47), which ensures proper folding of collagen, procollagen 1, precursor peptide of collagen 1 , as well as collagen 1 , one of the main components of the extra cellular matrix (ECM). Additionally, it has been shown that alpha smooth muscle actin $(\alpha-S m a)$, used as a marker for activated fibrogenic cells, is first downregulated (likely as a response to the initial tissue damage with the sectioning of the tissue) and then increases over time during culture, suggesting activation of hepatic stellate cells (Westra et al. 2014b).

Thus, as a first step, in order to use liver tissue slices to test potential impact on inflammation and the onset of fibrosis induced by nanoparticles, the effects of different culturing conditions on the tissue were compared. Because of the need of including serum proteins when testing nanomaterials to allow corona formation (Monopoli et al. 2012; Wang et al. $2013 \mathrm{~b}$ ), tissue slices maintained in medium supplemented with $5 \%$ fetal bovine serum (FBS) were tested, together with standard serum-free conditions, usually applied for optimal tissue maintenance (Olinga et al. 2001; de Graaf et al. 2010; Westra et al. 2014b; Gore et al. 2019). Furthermore, the results obtained in slices cultured for $72 \mathrm{~h}$ were compared to the results in slices maintained for the same time, but with the medium refreshed daily. Tissue viability, collagen staining and the expression of a panel of classic markers of fibrosis and inflammation were determined and compared for the different conditions (Fig. 1). IL-1 $\beta$ and IL-6 were chosen as commonly classified pro-inflammatory cytokines, while IL-4 and IL-10 represented anti-inflammatory cytokines (Cavaillon 2001).

The results showed that the viability of liver slices increased up to $72 \mathrm{~h}$ compared to freshly cut slices $(0 \mathrm{~h})$, and no differences were observed among slices maintained in serum-free medium and medium supplemented with $5 \%$ FBS, both with and without refreshing of the medium (Fig. 1a). As expected, liver slices overexpressed the fibrosis markers Hsp47 and Pcolla over time in all cases (Fig. 1b), while the expression of $\alpha$-Sma decreased as previously observed. No differences in gene expression of fibrosis markers were observed among slices cultured in the different conditions tested (in the presence of serum and/or with medium daily refreshed). Additionally, paraffin sections of liver slices were stained for collagen fibers using picro-sirius red staining (Fig. 1d). After $72 \mathrm{~h}$ of incubation, a mild increase in collagen staining was observed (Westra et al. 2014b). However, quantification of the Pro-Collagen I $\alpha 1$ in the medium is required to fully confirm potential activation of fibrosis (Gore et al. 2019). 
a

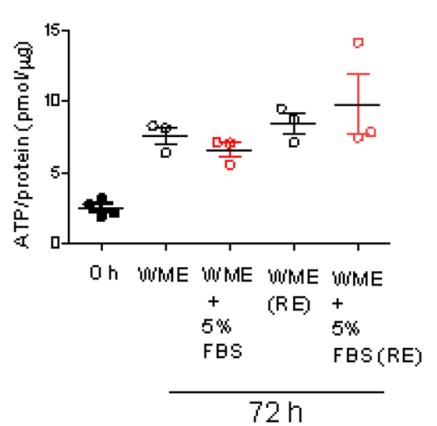

c

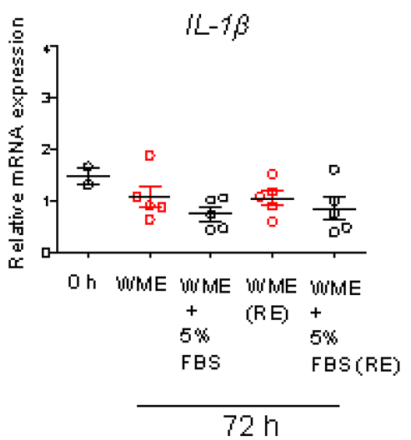

d b

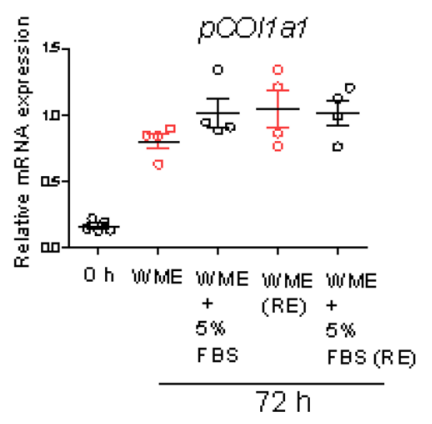

Fibrosis markers

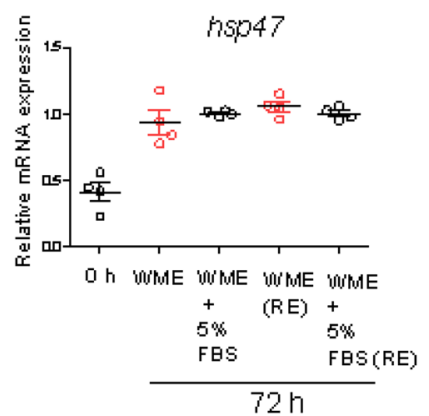

\section{Inflammation markers}
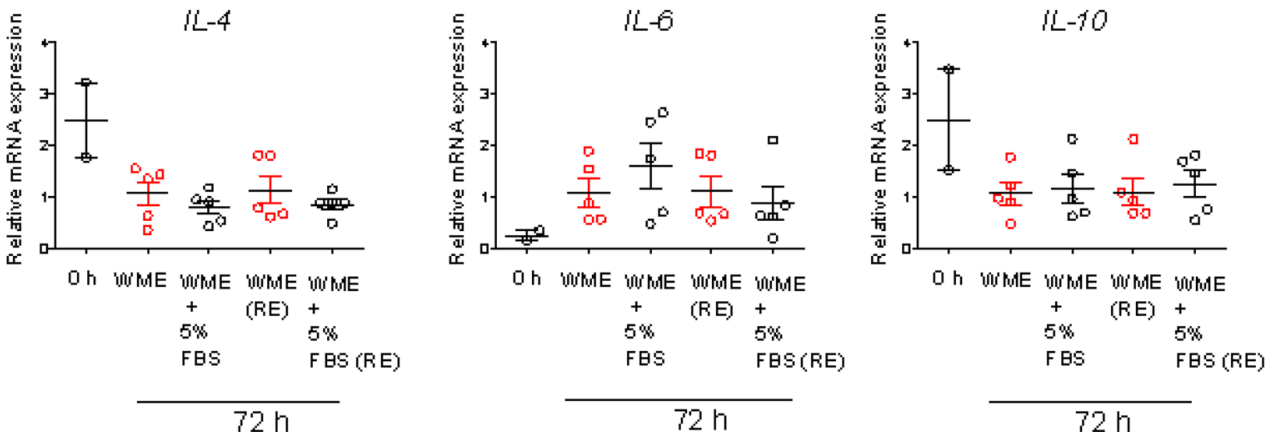

\section{Picro Sirius-red staining}

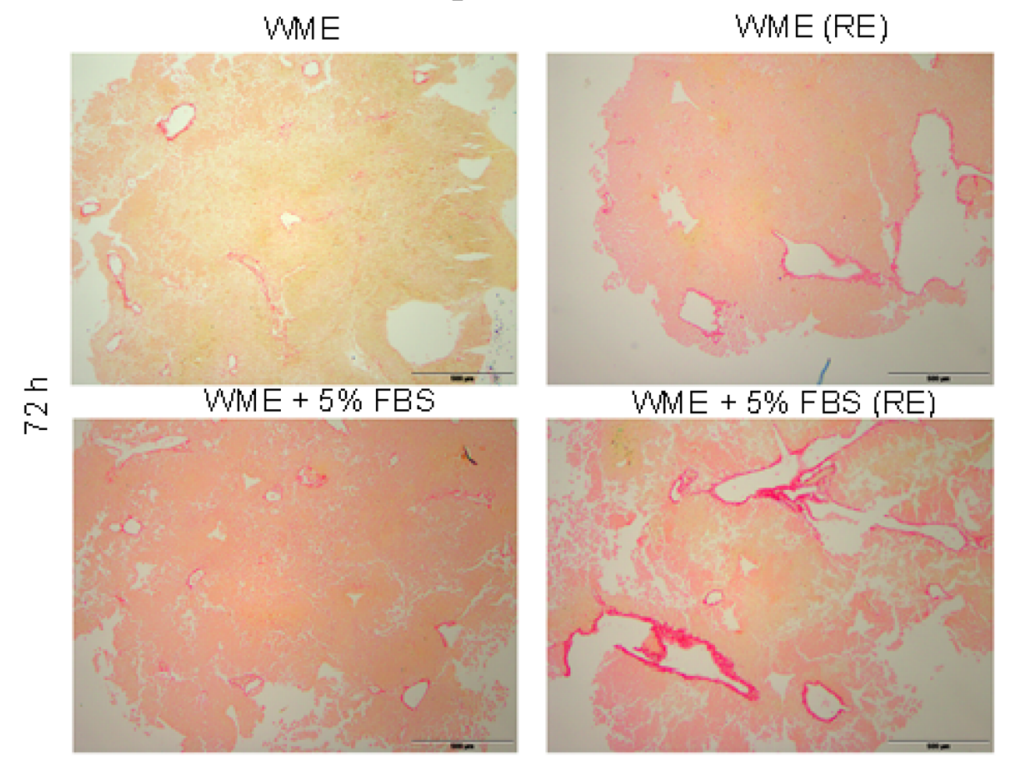

Fig. 1 Response of tissue slices to different growth conditions. Liver slices were cultured for $72 \mathrm{~h}$ in serum-free medium (WME), medium supplemented with 5\% FBS (WME +5\% FBS), daily-refreshed serum-free medium (WME RE) or daily-refreshed 5\% FBS medium [WME $+5 \%$ FBS (RE)] and tested for viability (a), the expression of fibrosis and inflammatory markers (b and c, respectively) and collagen staining (d). a Viability is expressed as the ATP content (pmol) normalized by amount of total protein $(\mu \mathrm{g})$. The results are the mean and standard error of the mean of 3-5 independent experiments. $\mathbf{b}$ and $\mathbf{c}$ The expression of selected markers is shown as fold induction over the expression levels in slices cultured in serum-free medium (without refreshing of the medium). The results are the mean and standard error of the mean of 4-5 independent experiments. The relative gene expression was determined by qRT-PCR and calculated using $\beta$-actin as housekeeping gene as described in the "Materials and methods" section. Kruskal-Wallis statistic followed by Dunnett's multiple comparisons test were performed on $\Delta C t$ values. $\mathbf{d}$ Paraffin sections of liver slices freshly cut $(0 \mathrm{~h})$, and maintained in culture for $72 \mathrm{~h}$ in serum-free medium (WME) or in medium supplemented with $5 \%$ FBS (WME + 5\% FBS) non refreshed or daily-refreshed (RE). Red: collagen fibers. Scale bar $=500 \mu \mathrm{m}$ 
Next, the expression of the inflammation markers $I L-4$ and $I L-10$ decreased, while the expression of $I L-6$ increased, when compared to slices at $t=0 \mathrm{~h}$ (Fig. 1c).

Taken together, these results suggest that the presence of $5 \%$ FBS did not significantly alter the viability of the slices and had only minor effects on the gene expression levels of $\alpha$-Sma and $I L-6$. No differences were detected when the culture medium was refreshed daily, nor on slices cultured in the presence of 5\% FBS, possibly because this is still a relatively low serum concentration. Given that nanoparticles will accumulate in the liver via the systemic circulation in full plasma, it will be important to repeat similar studies using much higher serum concentrations. In relation to this, the use of corona-coated nanoparticles in serum-free conditions, as we tested here, may be a good strategy to use a realistic corona formed in full serum or full plasma, while at the same time avoiding additional effects on tissue responses due to the presence of such high protein content.

\section{Exposure to amino-modified polystyrene $\mathrm{PS}-\mathrm{NH}_{2}$ nanoparticles}

As a first step, liver slices were exposed to $50 \mathrm{~nm}$ aminomodified polystyrene ( $\mathrm{PS}-\mathrm{NH}_{2}$ ), a well-studied model nanoparticle in nanosafety for toxicity induced by some positively charged objects (Kim et al. 2012; Wang et al. 2013a). PS- $\mathrm{NH}_{2}$ nanoparticles are known to induce inflammation and to have different impact on cells. When exposed to cells in the presence of biological fluids, thus covered by a corona, these nanoparticles have been shown to induce apoptosis (Xia et al. 2008; Lunov et al. 2011; Wang et al. 2013a). However, they can induce fast necrosis if added to cells in artificial serum-free conditions, due to direct interactions of their positively-charged surface with the cell membrane (Wang et al. 2013a). Thus, we exposed liver slices to these nanoparticles in serum-free conditions as a control, to confirm that inflammatory responses in the tissue could be detected.

Prior to exposure to tissue, dynamic light scattering (DLS) was used to characterize the $\mathrm{PS}-\mathrm{NH}_{2}$ dispersions formed in serum-free medium, as well as in medium with $5 \%$ FBS (in situ), and after isolation of corona-coated nanoparticles. The size distribution showed a mild sign of agglomeration for the dispersion in situ, but multiple peaks were observed for corona-coated nanoparticles in serum-free medium, suggesting that centrifugation for corona isolation led to particle agglomeration (Supplementary Figure S1). To avoid confusing results due to exposure to unstable dispersions or agglomerates, in this case we decided to expose liver slices only to PS- $\mathrm{NH}_{2}$ nanoparticles in medium supplemented with 5\% FBS or-for comparison as a control-in serum-free medium, with and without refreshing the nanoparticle dispersion daily.
We previously determined loss of viability over $72 \mathrm{~h}$ in liver slices exposed to PS- $\mathrm{NH}_{2}$ nanoparticles in situ and in serum-free medium when dispersions were not refreshed (Bartucci et al. 2020). Here, the results confirmed a strong decrease in viability also in slices exposed to these nanoparticles in daily-refreshed serum-free medium (Supplementary Figure S2). In relation to inflammation markers, exposure to PS- $\mathrm{NH}_{2}$ nanoparticles caused downregulation of $I L-1 \beta$ and $I L-10$ in all exposure conditions (Fig. 2), although the effect was not significant. Interestingly, upregulation of $I L$ 6 was observed in slices exposed to the nanoparticles in medium supplemented with 5\% FBS, as well as in serumfree medium. However, $I L-6$ expression increased up to 50 -fold when slices were exposed to these nanoparticles in serum-free medium and the dispersion was refreshed daily. This confirmed that, as expected, exposure to the bare nanoparticles in serum-free conditions led to a strong inflammatory response, and additionally clear effects due to ageing of the nanoparticle dispersions were present, thus inflammation was much stronger in slices exposed to daily-refreshed nanoparticle dispersions.

When testing the expression of fibrosis markers, a concentration-dependent decrease in the expression of Pcollal and $\alpha S m a$ was observed in slices exposed to nanoparticles in medium supplemented with 5\% FBS (Fig. 3). A slight increase was observed for the expression of $\mathrm{Hsp} 47$ and $\alpha \mathrm{Sma}$ with PS- $\mathrm{NH}_{2}$ in daily-refreshed serum-free medium, however this was not significant. Immunostaining of collagen I and sirius-red staining were also performed, and no evident alterations could be detected (Supplementary Figure S3).

Overall, these results allowed us to confirm-first of all - that tissue slices are a good model to test inflammatory responses induced by nanoparticles and - secondlythat the exposure conditions can strongly affect the response of the tissue to the nanoparticles. The presence of a corona is required to ensure realistic exposure and avoid inflammatory responses as a consequence of artificial exposure to serum-free bare nanoparticles. At the same time, additional effects due to ageing of the nanoparticle dispersion also need to be considered. Even though slices are cultured under gentle shaking (see "Materials and methods" section for details) which should limit effects due to nanoparticle sedimentation and settling of agglomerates, it is interesting to see that refreshing the nanoparticle dispersions led to much stronger effects on the slices. Similar ageing effects can have profound impact on the response of the tissue, as we observed here, and are particularly important when testing nanoparticles over a longer period.

\section{Exposure to PS-COOH nanoparticles}

Next, liver slices were exposed to $40 \mathrm{~nm}$ carboxylate-modified polystyrene (PS-COOH) nanoparticles. We previously 

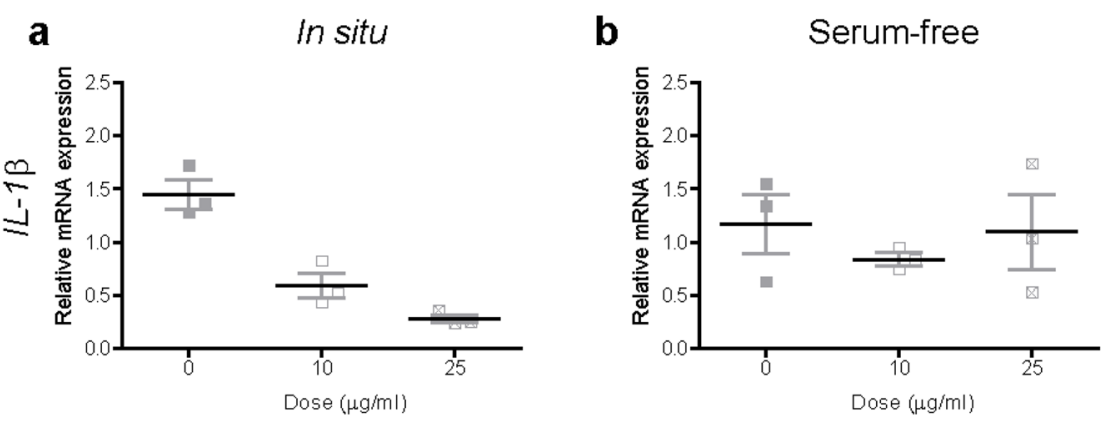

C

Serum-free refreshed
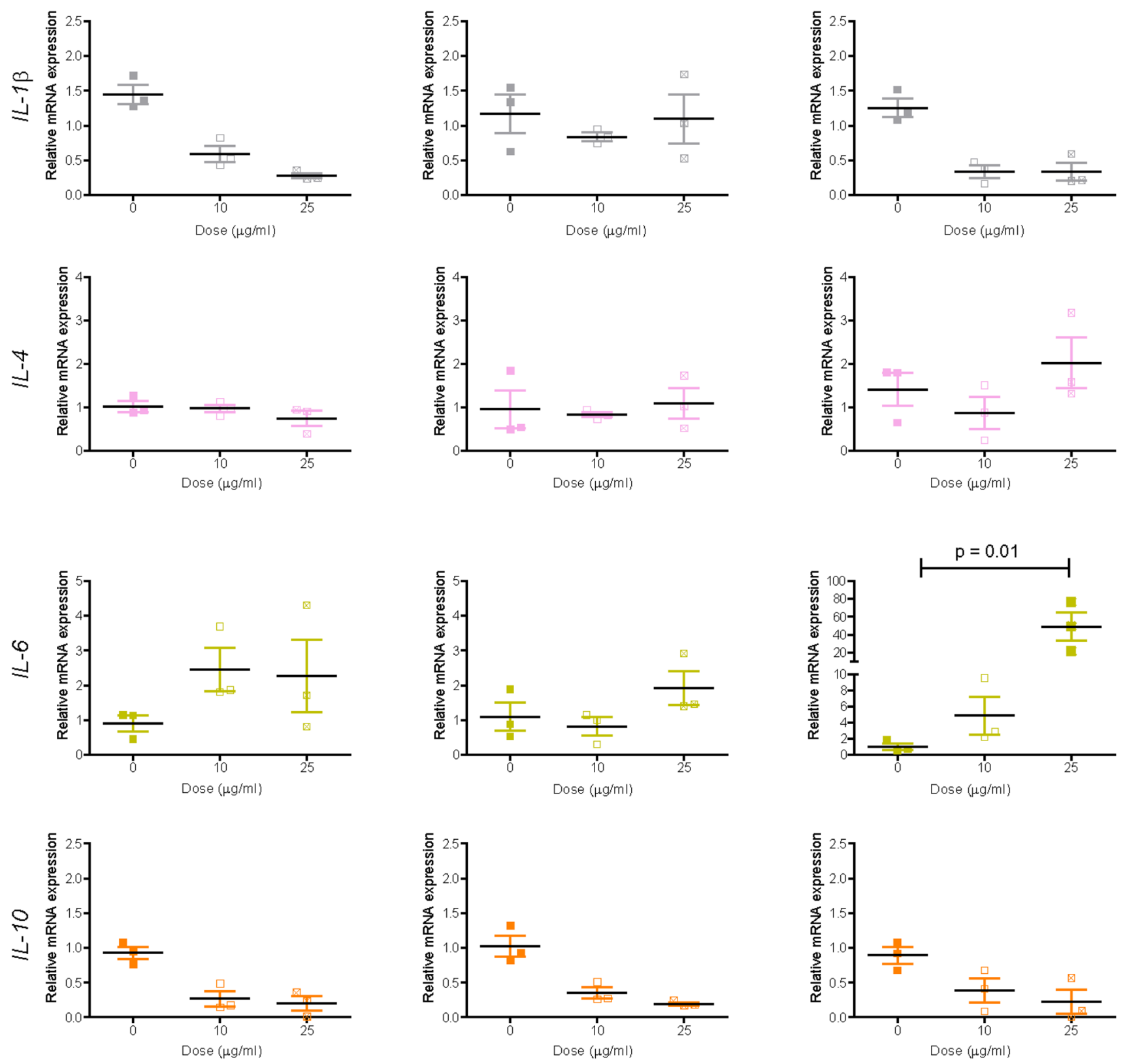

Fig. 2 Expression of inflammation markers after $\mathrm{PS}-\mathrm{NH}_{2}$ nanoparticle exposure. Liver slices were exposed for $72 \mathrm{~h}$ to $\mathrm{PS}-\mathrm{NH}_{2}$ in $\mathrm{WME}+5 \%$ FBS (a), serum-free medium (b) and daily-refreshed serum-free medium (c). The relative gene expression was determined by qRT-PCR and calculated using $\beta$-actin as housekeeping gene. The data are presented as the fold induction over the expression levels

showed by confocal microscopy and flow cytometry on cells recovered after tissue digestion that these nanoparticles are efficiently internalized in liver tissue slices, with a preferential accumulation in the Kupffer cells (Bartucci et al. 2020). PS-COOH are commonly used together with the PS- $\mathrm{NH}_{2}$ nanoparticles as model nanoparticles, usually considered nontoxic and toxic, respectively (Bexiga in slices cultured in serum-free medium (without refreshing of the medium), calculated as described in the "Materials and methods" section. The results are the mean and standard error of the mean of three independent experiments. Kruskal-Wallis statistic followed by Dunnett's multiple comparisons test were performed on $\Delta C t$ values

et al. 2011; Lunov et al. 2011; Loos et al. 2014). DLS data showed that homogenous dispersions could be obtained for nanoparticles dispersed in medium with 5\% FBS and also after isolation of corona-coated PS-COOH (Supplementary Figure S4). Therefore, both exposure conditions were tested on tissue slices, together with daily refreshed coronacoated PS-COOH dispersions. Tissue viability appeared 

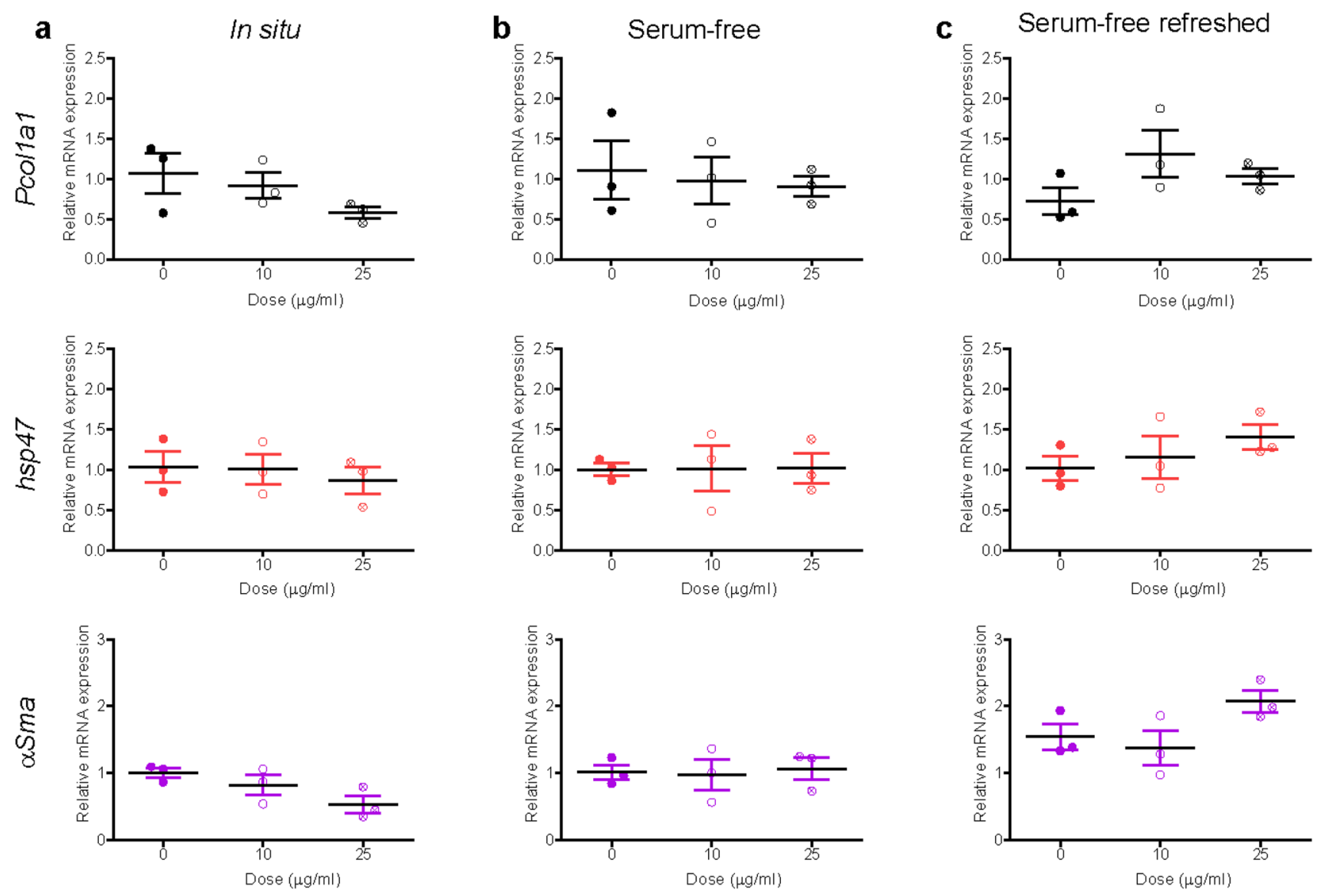

Fig. 3 Expression of fibrosis markers after $\mathrm{PS}^{-\mathrm{NH}_{2}}$ nanoparticle exposure. Liver slices were exposed for $72 \mathrm{~h}$ to $\mathrm{PS}-\mathrm{NH}_{2}$ in WME + 5\% FBS (a), in serum-free medium (b) and daily-refreshed serum-free medium $(\mathbf{c})$. The relative gene expression was determined by qRT-PCR and calculated using $\beta$-actin as housekeeping gene. The data are presented as the fold induction over the expression levels

unaffected by exposure to the nanoparticles in all conditions (Supplementary Figure S5). In relation to inflammation, a concentration-dependent downregulation was observed for $I L-1 \beta$ when slices were exposed to PS-COOH nanoparticles in situ. An increase in the expression of $I L-6$ was instead observed in slices exposed to the PS-COOH in medium with $5 \% \mathrm{FBS}$, as well as to corona-PS-COOH with the medium daily refreshed (Fig. 4). Fibrosis markers did not show any significant alteration (Fig. 5), in line with similar results by collagen staining (Supplementary Figure S6).

\section{Exposure to $\mathrm{SiO}_{2}$ nanoparticles}

Next to polystyrene, amorphous $50 \mathrm{~nm}$ silica $\left(\mathrm{SiO}_{2}\right)$ nanoparticles were chosen as an additional nanomaterial for this study because they are relevant for nanosafety studies and highly studied in vitro as well as in vivo for possible chronic effects (Arts et al. 2007; Park and Park 2009; Xie et al. 2010; Lesniak et al. 2012; Chan et al. 2017). We in slices cultured in serum-free medium (without refreshing of the medium), calculated as described in the "Materials and methods" section. The results are the mean and standard error of the mean of three independent experiments. Kruskal-Wallis statistic followed by Dunnett's multiple comparisons test were performed on $\Delta C t$ values.

previously determined uptake of $\mathrm{SiO}_{2}$ nanoparticles by liver tissue slices by confocal imaging (Bartucci et al. 2020). DLS analysis showed that these nanoparticles were well monodispersed in medium with 5\% FBS (Supplementary Figure S7) and, similarly, isolation of corona-coated $\mathrm{SiO}_{2}$ in serum-free conditions allowed us to obtain homogenous dispersions. Given the good stability of the corona-coated $\mathrm{SiO}_{2}$ and of the $\mathrm{SiO}_{2}$ nanoparticle dispersion in situ, liver slices were exposed to the nanoparticles in both conditions up to $72 \mathrm{~h}$. Furthermore, the isolated corona-coated $\mathrm{SiO}_{2}$ nanoparticles were also tested with daily refreshment of the dispersion.

A mild decay of viability was observed only in liver slices exposed to corona-coated $\mathrm{SiO}_{2}$ at the highest concentration (Supplementary Figure S8). When testing potential inflammatory responses (Fig. 6), an increase in $I L-6$ expression and small decrease of $I L-1 \beta$ were observed in liver slices exposed to $\mathrm{SiO}_{2}$ nanoparticles in situ. A mild decrease in $I L-10$ was observed in slices exposed to the highest concentration of corona-coated $\mathrm{SiO}_{2}$ when the dispersion was 

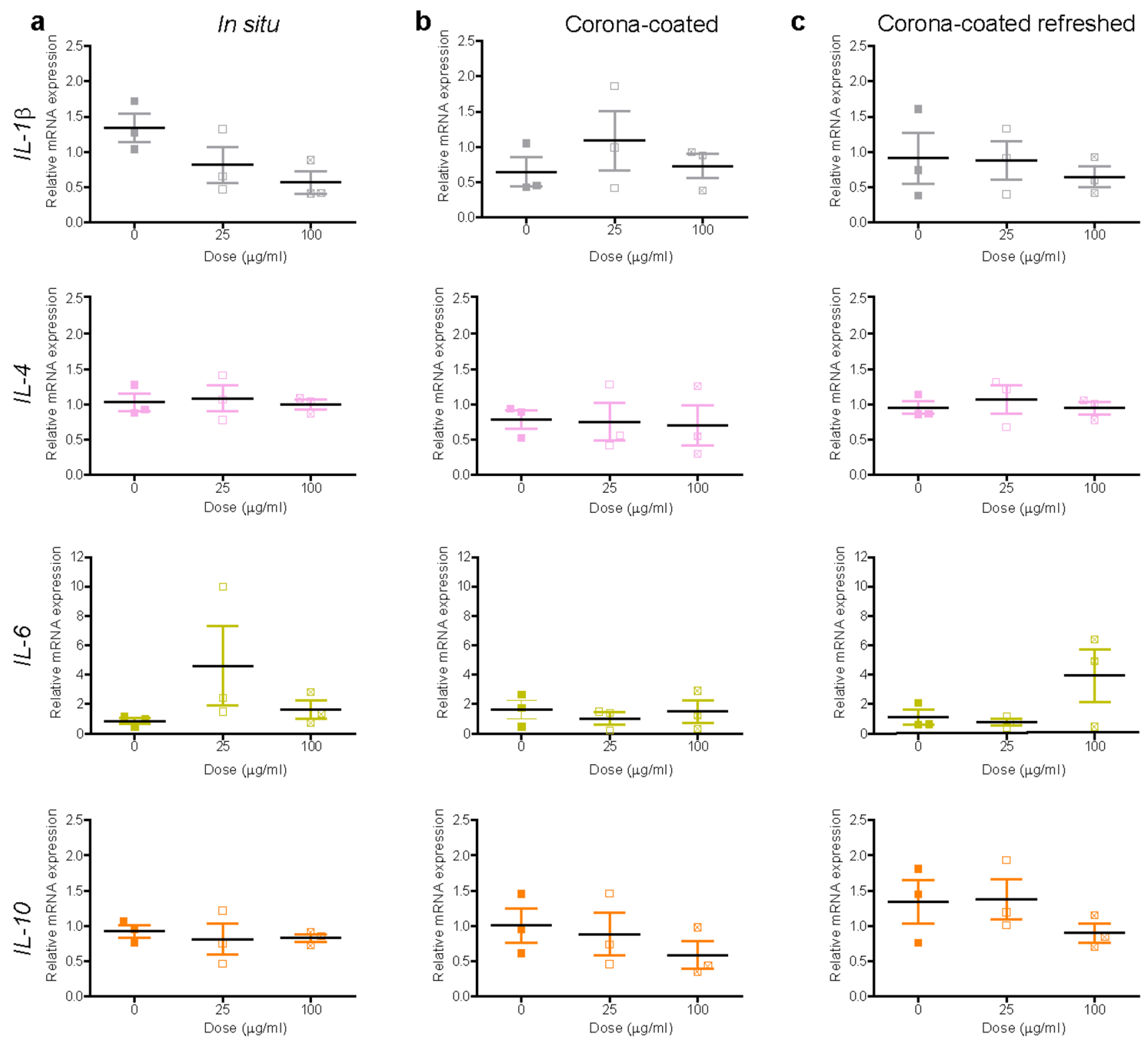

Fig. 4 Expression of inflammation markers after PS-COOH nanoparticle exposure. Liver slices were exposed for $72 \mathrm{~h}$ to $\mathrm{PS}-\mathrm{COOH}$ in $\mathrm{WME}+5 \% \mathrm{FBS}$ (a), and to isolated corona-coated PS-COOH in serum-free medium without (b) and with daily refreshment of the corona-coated PS-COOH dispersion (c). The relative gene expression was determined by qRT-PCR and calculated using $\beta$-actin as house- keeping gene. The data are presented as the fold induction over the expression levels in slices not exposed to nanoparticles, calculated as described in the "Materials and methods" section. The results are the mean and standard error of the mean of three independent experiments. Kruskal-Wallis statistic followed by Dunnett's multiple comparisons test were performed on $\Delta C t$ values refreshed daily, while $I L-4$ did not show any alteration. Similarly, analysis of fibrosis markers showed only a small increase in Pcollal expression in slices exposed to coronacoated $\mathrm{SiO}_{2}$ with and without refreshing of the dispersion, and a small increase in $\alpha$-Sma expression in slices exposed without refreshment of the dispersion (Fig. 7). Next, Tgf$\beta$ levels were also determined and staining for collagen I was performed (Supplementary Figures S9 and S10). No significant differences were observed among all conditions tested in respect to untreated slices.

Overall, these results indicated that no significant alterations in the tested inflammation and fibrosis markers were detected in liver slices exposed to silica nanoparticles. However a previous in vivo study showed that amorphous $\mathrm{SiO}_{2}$ nanoparticles can lead to fibrosis in the liver via oxidative stress, which in turn causes persistent inflammation and TGF- $\beta 1 / \mathrm{Smad} 3$ activation (Yu et al. 2017). This 


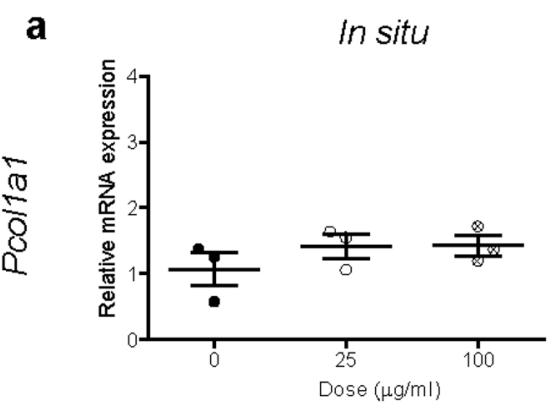

b
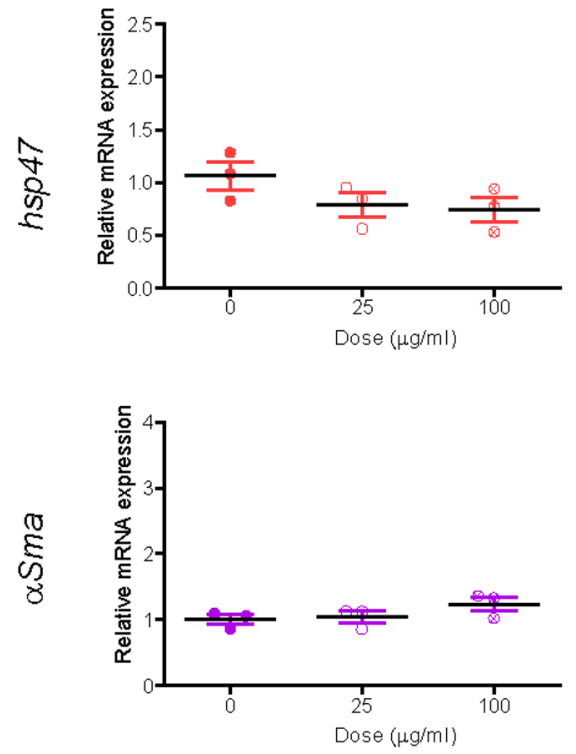

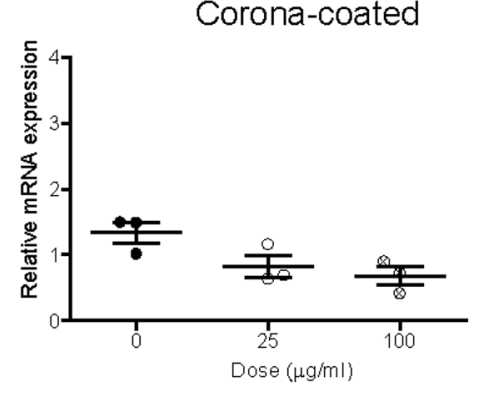

C
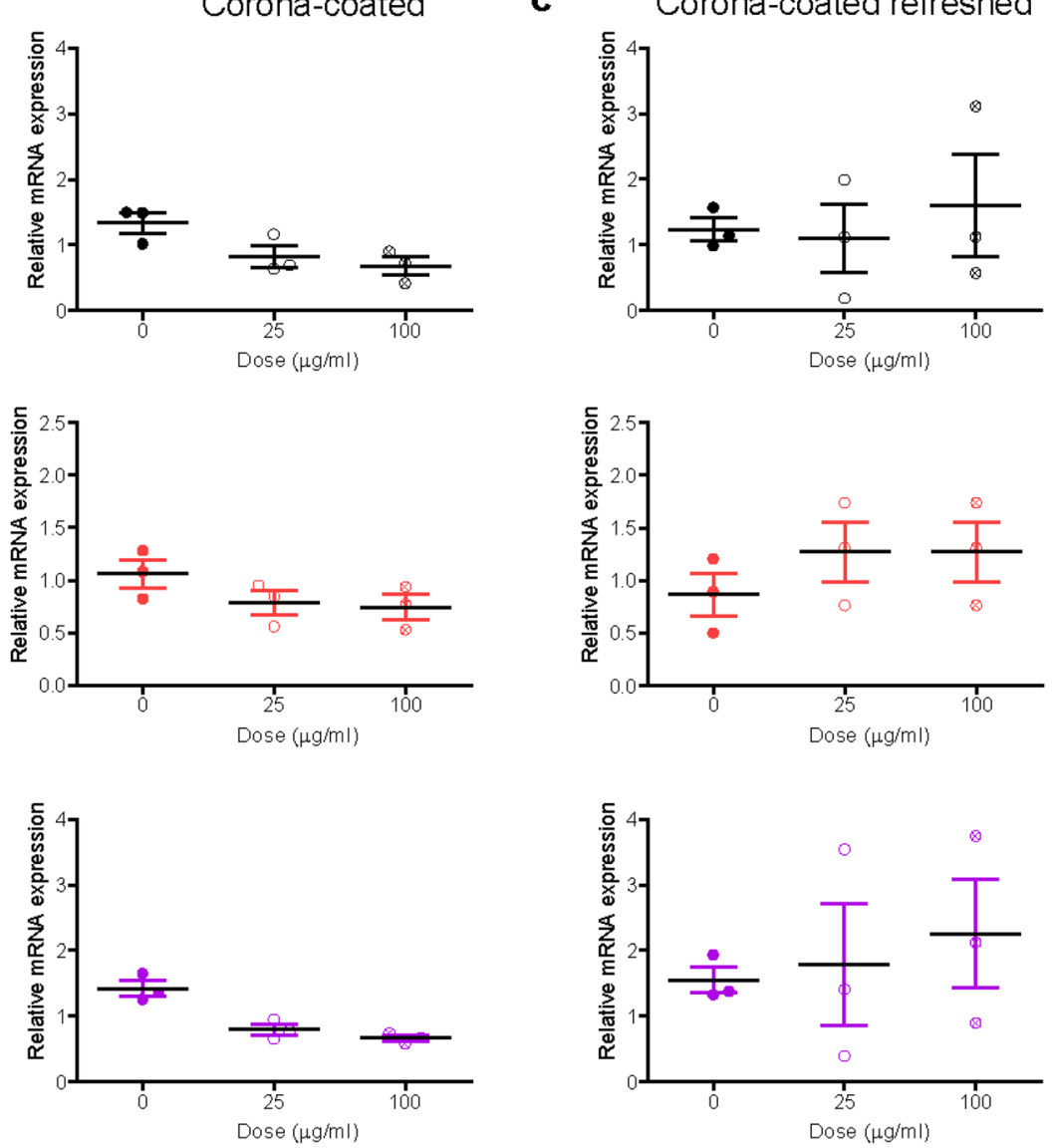

Fig. 5 Expression of fibrosis markers after PS-COOH nanoparticle exposure. Liver slices were exposed for $72 \mathrm{~h}$ to $\mathrm{PS}-\mathrm{COOH}$ in $\mathrm{WME}+5 \%$ FBS (a), and to isolated corona-coated PS-COOH in serum-free medium without (b) and with daily refreshment of the corona-coated PS-COOH dispersion (c). The relative gene expression was determined by qRT-PCR and calculated using $\beta$-actin as house- keeping gene. The data are presented as the fold induction over the expression levels in slices not exposed to nanoparticles, calculated as described in the "Materials and methods" section. The results are the mean and standard error of the mean of three independent experiments. Kruskal-Wallis statistic followed by Dunnett's multiple comparisons test were performed on $\Delta C t$ values in vivo study was performed over a period of 15-60 days. The much longer time-scale may suggest that in our case the exposure time was too short to observe similar changes at mRNA and protein levels in the tissue.

\section{Exposure to $\mathrm{TiO}_{2}$ nanoparticles}

Similar to $\mathrm{SiO}_{2}$ nanoparticles, titania $\left(\mathrm{TiO}_{2}\right)$ nanoparticles were selected as another well-known model nanomaterial, broadly studied in nanosafety in relation to inflammation and fibrosis (Hong and Zhang 2016; Suker and Jasim 2018; Valentini et al. 2019). Prior to mRNA expression studies, $\mathrm{TiO}_{2}$ nanoparticles were characterized by DLS (Supplementary Figure S11). The DLS results showed multiple peaks, indicative of aggregation. The same was observed when nanoparticles were simply resuspended in PBS or in Milli-Q water (data not shown). Given the strong agglomeration, isolation of corona- $\mathrm{TiO}_{2}$ was not attempted, however to test for potential induction of fibrosis and inflammation, liver slices were exposed to the $\mathrm{TiO}_{2}$ nanoparticles in medium supplemented with 5\% FBS with and without daily refreshing of the dispersion. No decrease of viability was observed after exposure to increasing doses of $\mathrm{TiO}_{2}$ nanoparticles in any of the tested conditions (Supplementary Figure S12). Similarly, no significant mRNA alterations were observed for both inflammation and fibrosis markers (Figs. 8, 9 and Supplementary Figure S13). Only a dose-dependent decrease was observed for $I L-10$, yet not significant (probably also because of the small number of replicates). Also in this case, collagen I and Sirius-red stainings were performed, but no evident alterations were observed (Supplementary Figure S14).

Similar to $\mathrm{SiO}_{2}$ nanoparticles, previous in vivo studies which reported induction of fibrosis upon exposure to $\mathrm{TiO}_{2}$ nanoparticles were carried out for up to a few months 

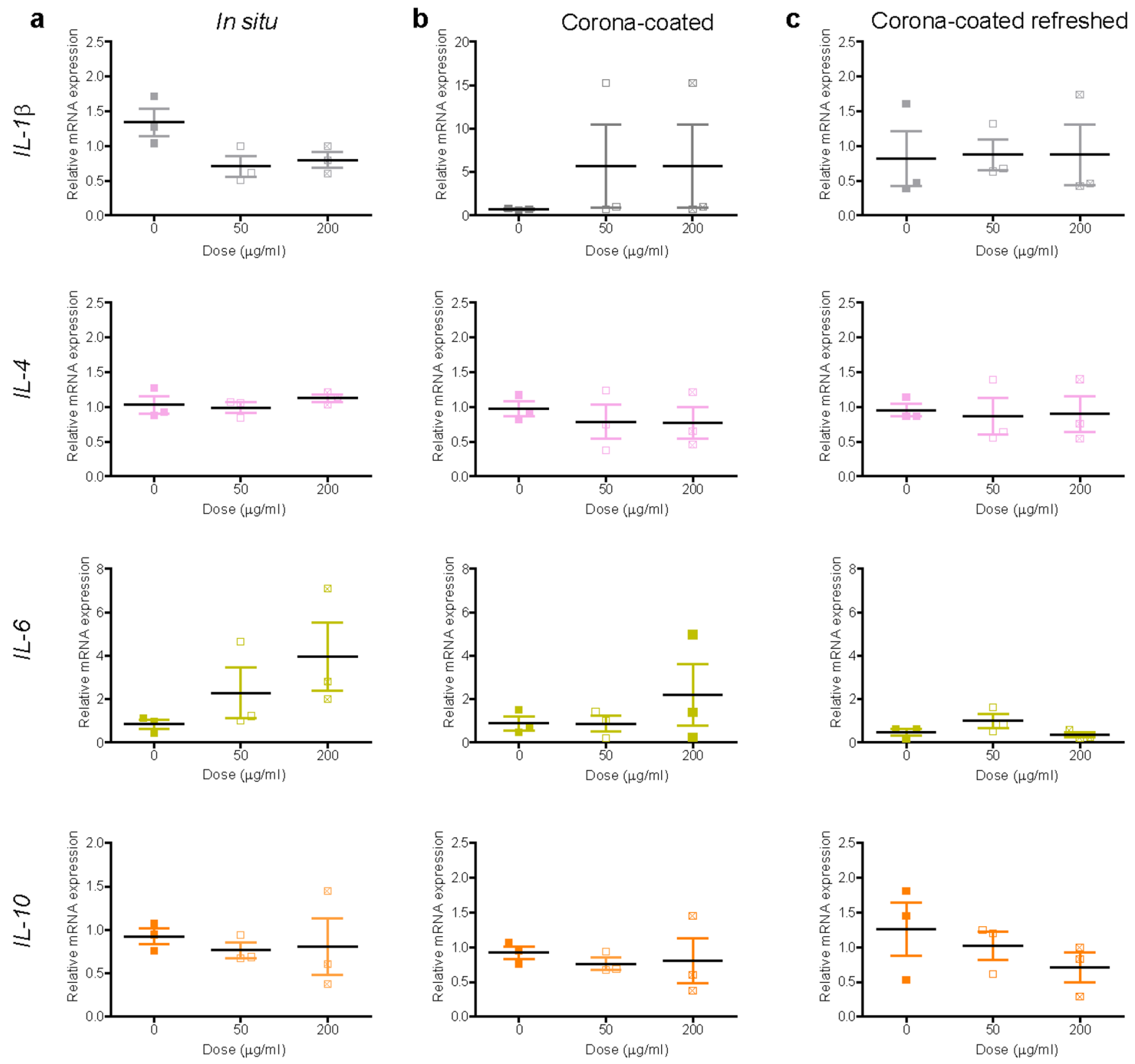

Fig. 6 Expression of inflammation markers after $\mathrm{SiO}_{2}$ nanoparticle exposure. Liver slices were exposed for $72 \mathrm{~h}$ to $\mathrm{SiO}_{2}$ in WME $+5 \%$ FBS (a), and to isolated corona-coated $\mathrm{SiO}_{2}$ in serum-free medium without (b) and with (c) daily refreshment of the corona-coated $\mathrm{SiO}_{2}$ dispersion. The relative gene expression was determined by qRT-PCR and calculated using $\beta$-actin as housekeeping gene. The data are pre-

(Chen et al. 2009; Hong and Zhang 2016; Suker and Jasim 2018). Thus, it is likely that much longer timescales are required to detect similar responses. sented as the fold induction over the expression levels in slices not exposed to nanoparticle, calculated as described in the "Materials and methods" section. The results are the mean and standard error of the mean of three independent experiments. Kruskal-Wallis statistic followed by Dunnett's multiple comparisons test were performed on $\Delta C t$ values

\section{Discussion}

A central discussion in the toxicity field has always been the relevance of the models that can be used for long term studies (Pearson 1986; DelRaso 1993; Holmes et al. 2010; Krewski et al. 2010; Soldatow et al. 2013; Mahony et al. 2018). Naturally, this applies also to the nanosafety field (Krug 2014; Burden et al. 2017; Drasler et al. 2017; 
a

In situ
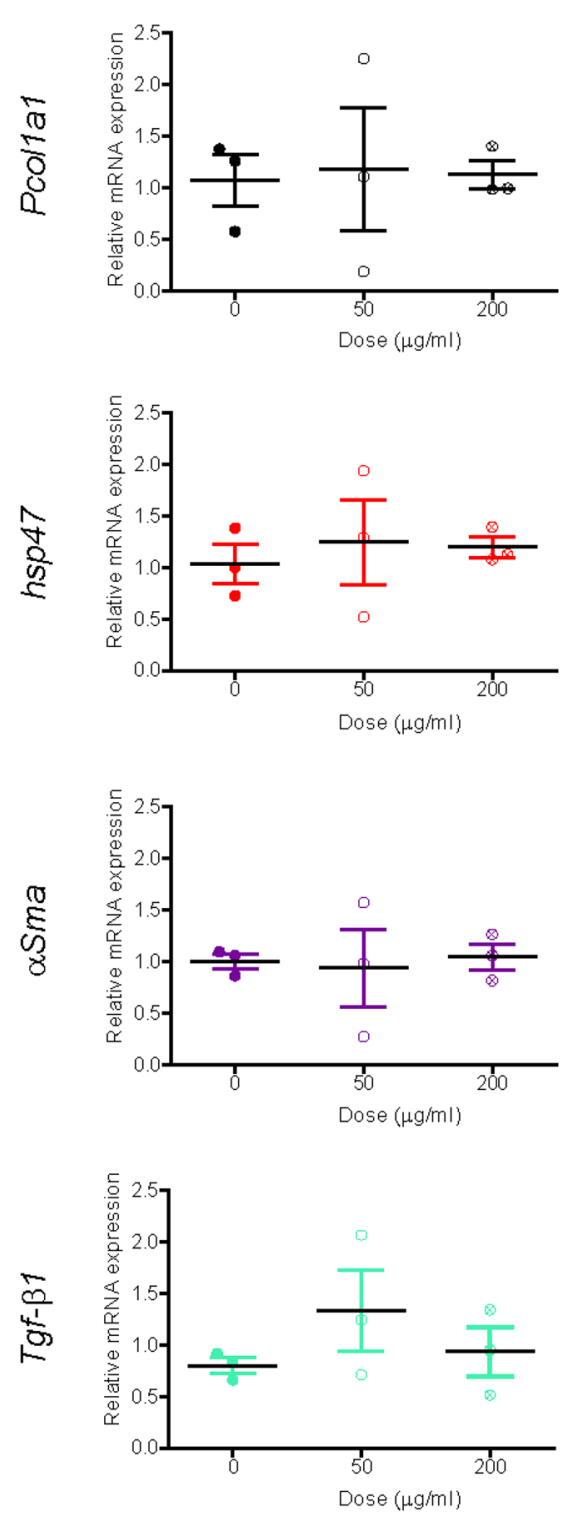

b
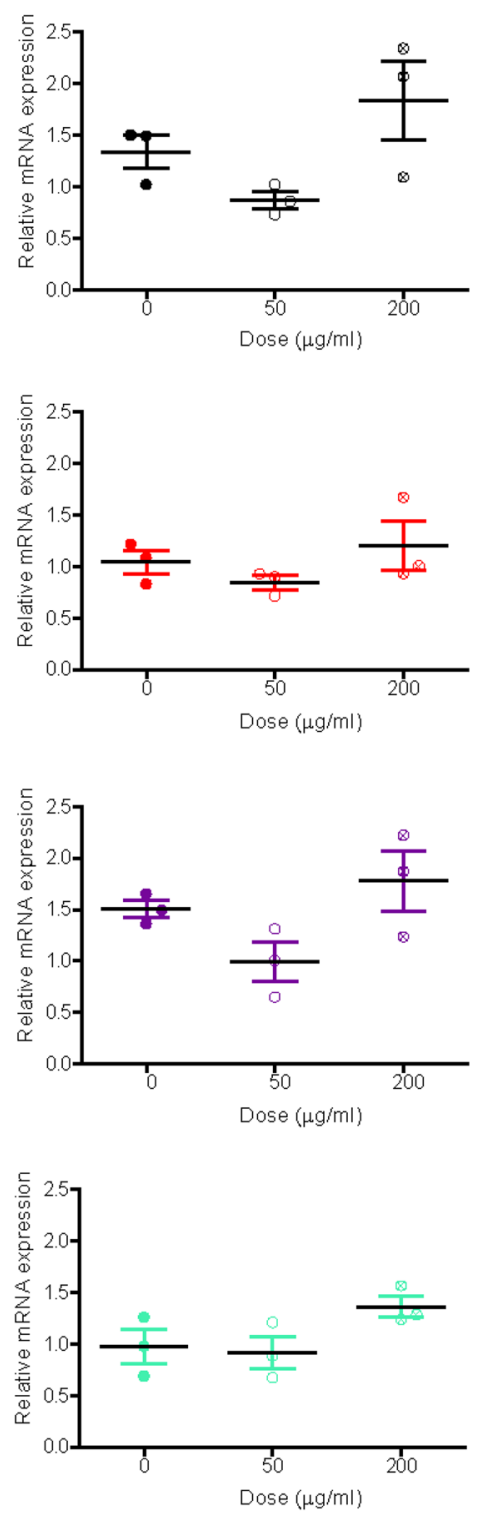

c

Corona-coated refreshed
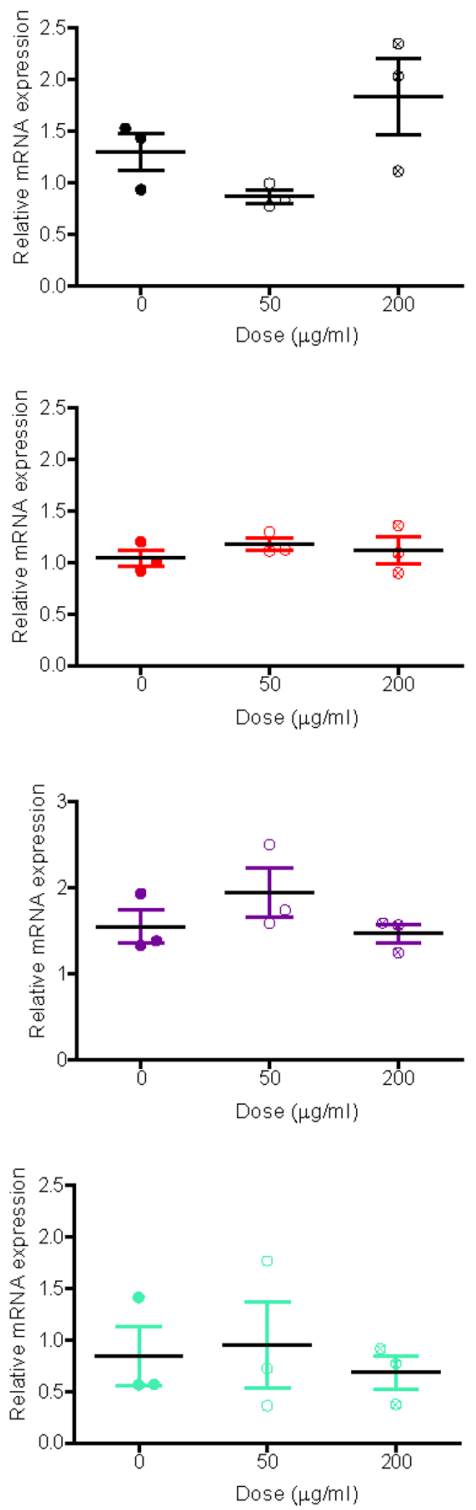

Fig. 7 Expression of fibrosis markers after $\mathrm{SiO}_{2}$ nanoparticle exposure. Liver slices were exposed for $72 \mathrm{~h}$ to $\mathrm{SiO}_{2}$ in WME+5\% FBS (a), and to isolated corona-coated $\mathrm{SiO}_{2}$ in serum-free medium without (b) and with (c) daily refreshment of the corona-coated $\mathrm{SiO}_{2}$ dispersion. The relative gene expression was determined by qRT-PCR and calculated using $\beta$-actin as housekeeping gene. The data are pre-

Accomasso et al. 2018; Guggenheim et al. 2018; Singh et al. 2019). There is an urgent need to optimize and validate good models that can be used to translate acute nanoparticle responses, as generally investigated in vitro, and chronic effects, usually studied in vivo. Several advanced in vitro models have been explored for this purpose, but it appears difficult to identify the ideal model that could allow resembling and connecting both in vitro and in vivo results. The cellular complexity and cell architecture of complex sented as the fold induction over the expression levels in slices not exposed to nanoparticles, calculated as described in the "Materials and methods" section. The results are mean and standard error of the mean of three independent experiments. Kruskal-Wallis statistic followed by Dunnett's multiple comparisons test were performed on $\Delta C t$ values

in vivo environments remains challenging to be reproduced in vitro, while the limited timeframe that can be explored using common in vitro models represents another obstacle, and is typically even more limited for advanced in vitro systems, as also the tissue slices used for this study (here cultured for up to $72 \mathrm{~h}$ ). Furthermore, when testing nanomaterials other important factors need to be considered to extract meaningful information, such as the inclusion of corona and additional effects due to ageing of dispersions in biological 
Fig. 8 Expression of inflammation markers after $\mathrm{TiO}_{2}$ nanoparticle exposure. Liver slices were exposed for $72 \mathrm{~h}$ to $\mathrm{TiO}_{2}$ in WME + 5\% FBS without (a) and with (b) daily refreshment of the dispersion. The relative gene expression was determined by qRT-PCR and calculated using $\beta$-actin as housekeeping gene. The data are presented as the fold induction over the expression levels in slices not exposed to nanoparticles, calculated as described in the "Materials and methods" section. The results are the mean and standard error of the mean of three independent experiments. Kruskal-Wallis statistic followed by Dunnett's multiple comparisons test were performed on the $\Delta C t$ values

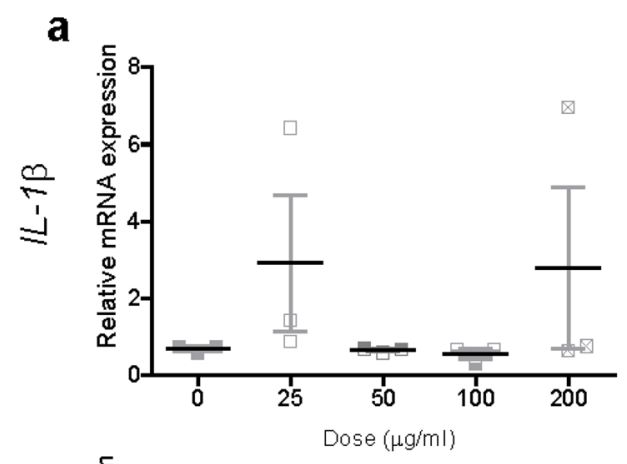

b
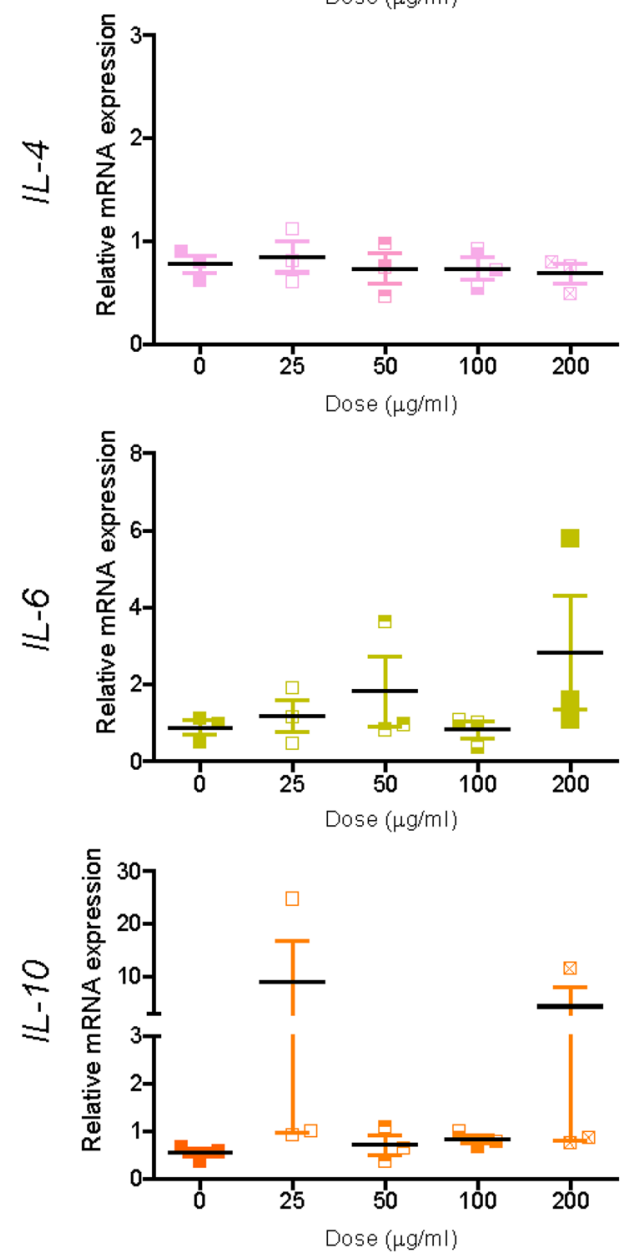
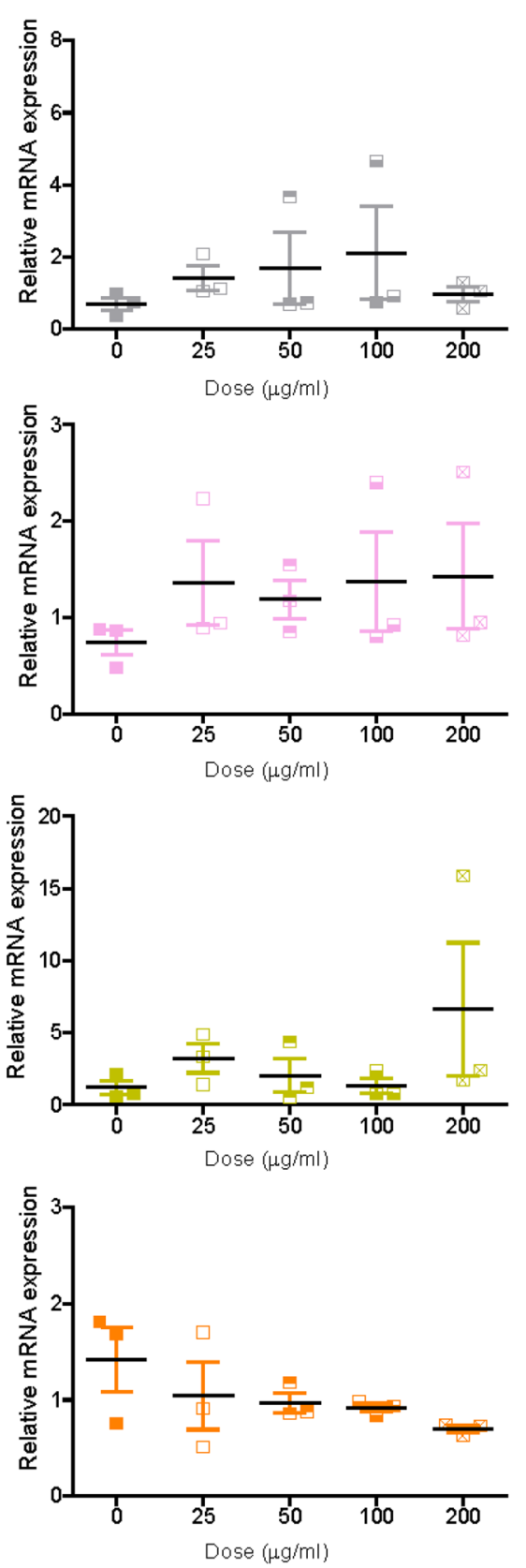

conditions (Kuchibhatla et al. 2012; Lesniak et al. 2012; Monopoli et al. 2012; Gubicza et al. 2013; Jasbi and Dorranian 2016; Lu et al. 2017). These factors, altogether, make studies of chronic nanoparticle impact in advanced models highly challenging.

Within this context, tissue liver slices represent a wellestablished 3D model in which the natural composition and organization of cells are maintained intact ex vivo (Olinga and Schuppan 2013). Because of this, we decided to attempt a long-term nanoparticle exposure in tissue slices to study potential impact in a more complex model. Even though this model can be used for only up to $72 \mathrm{~h}$, given the natural activation of fibrosis markers observed in tissue slices during culture, we were interested to determine nanoparticle interference with the early onset of fibrosis. A panel of different nanomaterials well studied in nanosafety was selected, and inflammation and fibrosis markers were monitored.

In summary, our results showed that liver tissue slices were able to respond to known toxic and pro-inflammatory nanoparticles ex vivo, suggesting they can be used as an appropriate model to test potential inflammatory responses induced by nanoparticles. Moreover, we confirmed once more the importance of including biological fluids such as serum to allow corona formation and avoid artifacts due to 
Fig. 9 Expression of fibrosis markers after $\mathrm{TiO}_{2}$ nanoparticle exposure. Liver slices were exposed for $72 \mathrm{~h}$ to $\mathrm{TiO}_{2}$ in WME + 5\% FBS without (a) and with (b) daily refreshment of the dispersion. The relative gene expression was determined by RT-qPCR and calculated using $\beta$-actin as housekeeping gene. The data are presented as the fold induction over the expression levels in slices not exposed to nanoparticles, calculated as described in the "Materials and methods" section. The results are mean $o$ and standard error of the mean of three independent experiments. Kruskal-Wallis statistic followed by Dunnett's multiple comparisons test were performed on $\Delta C t$ values
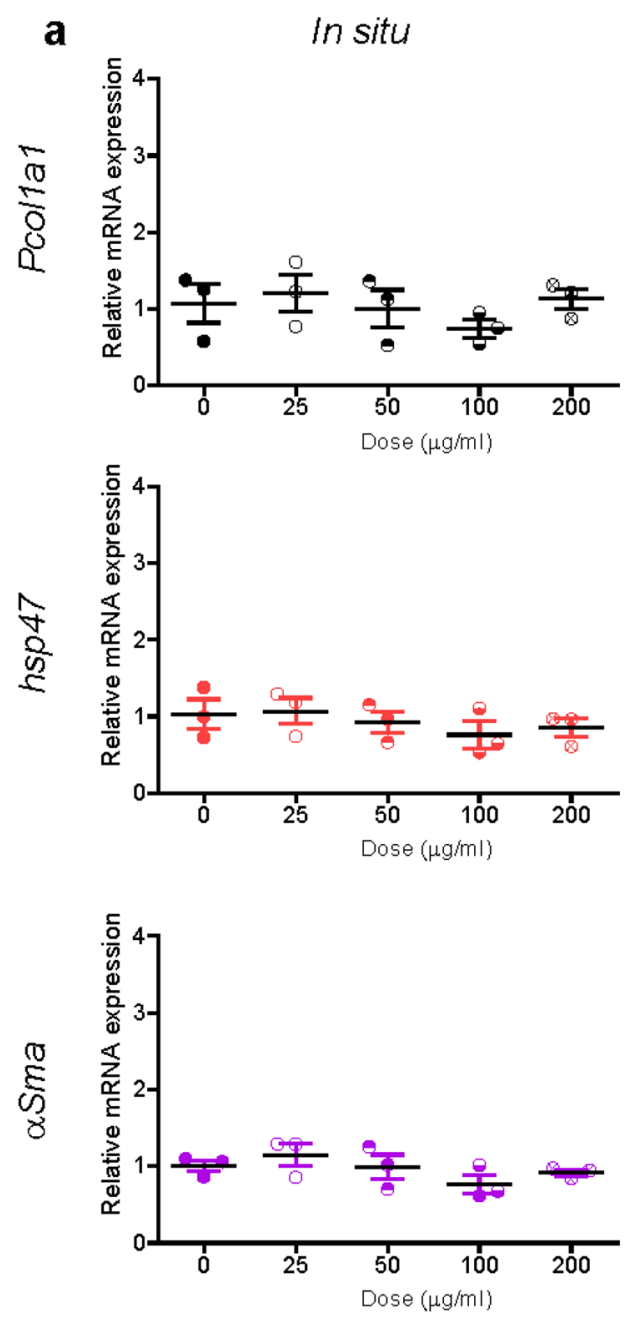

b
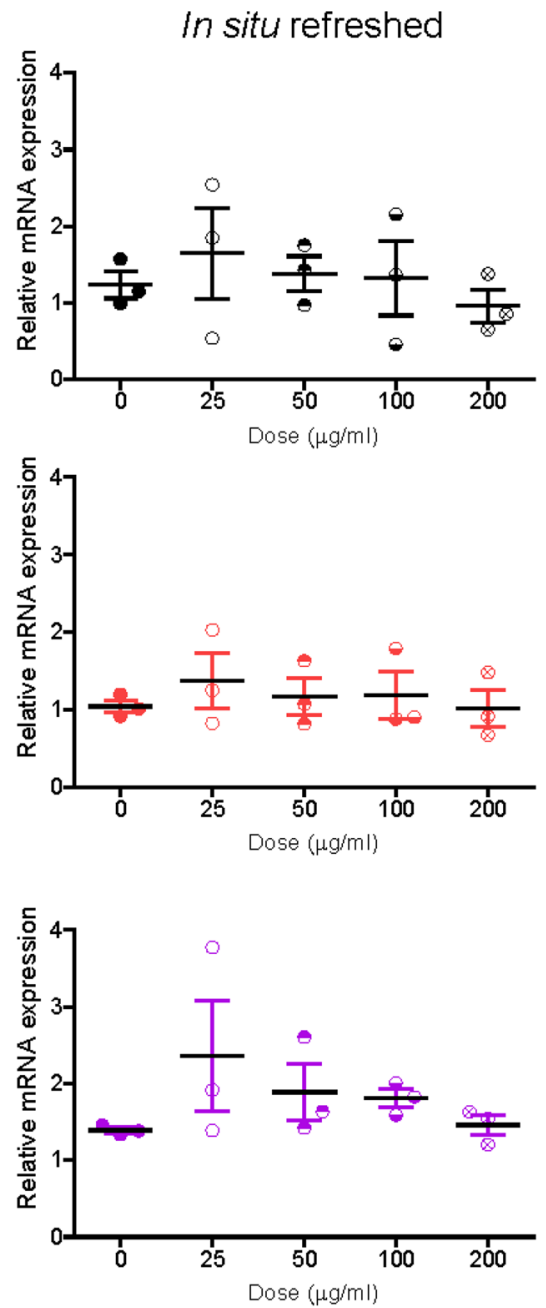

direct interactions with bare particles, usually associated with toxicity (Ge et al. 2011; Lesniak et al. 2012; Duan et al. 2015). Liver tissue will always be in contact with nanoparticles modified by protein adsorption from the surrounding environment (likely serum from the systemic circulation) and a serum-free condition will never really occur in the liver in vivo. Furthermore, we demonstrated that ageing of nanoparticle dispersions in biological conditions is another factor that needs to be taken into account and explicitly tested, especially when attempting to study long-term effects of nanomaterials. Nanoparticle dispersion ageing effects were already visible over $72 \mathrm{~h}$ exposure, as in our case.

Nevertheless, no alteration in fibrosis markers was observed for all nanoparticles and exposure conditions tested, even with $\mathrm{SiO}_{2}$ and $\mathrm{TiO}_{2}$ nanoparticles for which in vivo studies reported the capacity to induce fibrosis in chronic exposure (Chen et al. 2009; Hong and Zhang 2016; Yu et al. 2017; Suker and Jasim 2018). Liver slices are known to spontaneously develop the early onset of fibrosis, but it is also known that if pro-fibrotic factors are added to medium, the condition is exacerbated (Westra et al. 2014b).
Thus, the model is known to respond well to fibrotic stimuli. However, given the much longer timeframe for which fibrosis induced by nanoparticles was reported (Chen et al. 2009; Hong and Zhang 2016; Yu et al. 2017; Suker and Jasim 2018), it is most likely that longer exposure times should be tested to be able to observe similar effects. The maintenance of mouse liver slices has currently been optimized up to $72 \mathrm{~h}$, but - thanks to further optimization of the growth conditions - it has been shown that rat and human liver slices can now be maintained in culture for up to 5 days (Starokozhko et al. 2015, 2017). It would be interesting to expand this investigation using rat and human liver slices to be able to test longer exposure times, as well as to compare species-specific differences. Similarly, coronas formed at higher serum content more closely resembling plasma protein concentrations could be tested, as well as other nanoparticles such as copper oxide, zinc oxide, silver and ceria nanoparticles, which may have different modes of action and may show impact on the tissue already at $72 \mathrm{~h}$.

In conclusion, in the present study we show that precision-cut tissue liver slices are a model with great potential 
to study nanoparticle impact in a better in vivo-like environment, opening up new opportunities to discriminate various effects involved in nanoparticle exposure in real tissue. While we show that tissue slices can be used to detect inflammatory responses, fibrotic responses induced by nanoparticles have been reported only after much longer exposure times than what is currently possible with this model. Developing appropriate models for long-term studies while reproducing the complexity of real tissue in vitro remains an important challenge and urgent need in the field, to be able to answer on potential long-term effects on nanoparticles.

Supplementary Information The online version contains supplementary material available at https://doi.org/10.1007/s00204-021-02992-7.

Acknowledgements M.H. de Jager is kindly acknowledged for technical help with organ extraction and preparation, and C. Reker-Smit for the optimization of collagen staining. A.S. and Y.L.B. also acknowledge the University of Groningen for additional funding (Rosalind Franklin Fellowship).

\section{Compliance with ethical standards}

Conflict of interest The authors declare that have no competing interests.

Open Access This article is licensed under a Creative Commons Attribution 4.0 International License, which permits use, sharing, adaptation, distribution and reproduction in any medium or format, as long as you give appropriate credit to the original author(s) and the source, provide a link to the Creative Commons licence, and indicate if changes were made. The images or other third party material in this article are included in the article's Creative Commons licence, unless indicated otherwise in a credit line to the material. If material is not included in the article's Creative Commons licence and your intended use is not permitted by statutory regulation or exceeds the permitted use, you will need to obtain permission directly from the copyright holder. To view a copy of this licence, visit http://creativecommons.org/licenses/by/4.0/.

\section{References}

Accomasso L, Cristallini C, Giachino C (2018) Risk assessment and risk minimization in nanomedicine: a need for predictive, alternative, and 3Rs strategies. Front Pharmacol 9:228. https://doi. org/10.3389/fphar.2018.00228

Ajdary M, Moosavi M, Rahmati M et al (2018) Health concerns of various nanoparticles: a review of their in vitro and in vivo toxicity. Nanomaterials 8:634. https://doi.org/10.3390/nano8090634

Alépée N (2014) State-of-the-art of 3D cultures (organs-on-a-chip) in safety testing and pathophysiology. ALTEX 441-477. https://doi. org/https://doi.org/10.14573/altex.1406111

Armstead AL, Li B (2016) Nanotoxicity: emerging concerns regarding nanomaterial safety and occupational hard metal (WC-Co) nanoparticle exposure. Int J Nanomed 11:6421-6433. https://doi. org/10.2147/IJN.S121238

Arts JHE, Muijser H, Duistermaat E et al (2007) Five-day inhalation toxicity study of three types of synthetic amorphous silicas in
Wistar rats and post-exposure evaluations for up to 3 months. Food Chem Toxicol 45:1856-1867. https://doi.org/10.1016/j. fct.2007.04.001

Bartucci R, Åberg C, Melgert BN et al (2020) Time-resolved quantification of nanoparticle uptake, distribution, and impact in precision-cut liver slices. Small 16:1906523. https://doi.org/10.1002/ smll.201906523

Bexiga MG, Varela JA, Wang F et al (2011) Cationic nanoparticles induce caspase 3-, 7- and 9-mediated cytotoxicity in a human astrocytoma cell line. Nanotoxicology 5:557-567. https://doi. org/10.3109/17435390.2010.539713

Böhmert L, König L, Sieg H et al (2018) In vitro nanoparticle dosimetry for adherent growing cell monolayers covering bottom and lateral walls. Part Fibre Toxicol 15:42. https://doi.org/10.1186/ s12989-018-0278-9

Burden N, Aschberger K, Chaudhry Q et al (2017) The 3Rs as a framework to support a 21 st century approach for nanosafety assessment. Nano Today 12:10-13. https://doi.org/10.1016/j.nanto d.2016.06.007

Casals E, Pfaller T, Duschl A et al (2010) Time Evolution of the Nanoparticle Protein Corona. ACS Nano 4:3623-3632. https://doi. org/10.1021/nn901372t

Cavaillon JM (2001) Pro-versus anti-inflammatory cytokines: myth or reality. Cell Mol Biol Noisy Gd Fr 47:695-702

Chan W-T, Liu C-C, Chiang Chiau J-S et al (2017) In vivo toxicologic study of larger silica nanoparticles in mice. Int J Nanomed 12:3421-3432. https://doi.org/10.2147/IJN.S126823

Chen J, Dong X, Zhao J, Tang G (2009) In vivo acute toxicity of titanium dioxide nanoparticles to mice after intraperitioneal injection. J Appl Toxicol 29:330-337. https://doi.org/10.1002/jat.1414

Cho EC, Zhang Q, Xia Y (2011) The effect of sedimentation and diffusion on cellular uptake of gold nanoparticles. Nat Nanotechnol 6:385-391. https://doi.org/10.1038/nnano.2011.58

de Graaf IA, Groothuis GM, Olinga P (2007) Precision-cut tissue slices as a tool to predict metabolism of novel drugs. Expert Opin Drug Metab Toxicol 3:879-898. https://doi.org/10.1517/17425 255.3.6.879

de Graaf IAM, Olinga P, de Jager MH et al (2010) Preparation and incubation of precision-cut liver and intestinal slices for application in drug metabolism and toxicity studies. Nat Protoc 5:1540 1551. https://doi.org/10.1038/nprot.2010.111

De Jong WH, Hagens WI, Krystek P et al (2008) Particle sizedependent organ distribution of gold nanoparticles after intravenous administration. Biomaterials 29:1912-1919. https://doi. org/10.1016/j.biomaterials.2007.12.037

DelRaso NJ (1993) In vitro methodologies for enhanced toxicity testing. Toxicol Lett 68:91-99. https://doi.org/10.1016/03784274(93)90122-E

Devasena T (2017) Nanotoxicity and risk assessment. Therapeutic and diagnostic nanomaterials. Springer Singapore, Singapore, pp 53-59

Dragoni S, Franco G, Regoli M et al (2012) Gold nanoparticles uptake and cytotoxicity assessed on rat liver precision-cut slices. Toxicol Sci 128:186-197. https://doi.org/10.1093/toxsci/kfs 150

Drasler B, Sayre P, Steinhäuser KG et al (2017) In vitro approaches to assess the hazard of nanomaterials. NanoImpact 8:99-116. https ://doi.org/10.1016/j.impact.2017.08.002

Duan G, Kang S, Tian X et al (2015) Protein corona mitigates the cytotoxicity of graphene oxide by reducing its physical interaction with cell membrane. Nanoscale 7:15214-15224. https://doi. org/10.1039/C5NR01839K

Feliu N, Sun X, Alvarez Puebla RA, Parak WJ (2017) Quantitative particle-cell interaction: some basic physicochemical pitfalls. Langmuir 33:6639-6646. https://doi.org/10.1021/acs.langm uir.6b04629 
Ge C, Du J, Zhao L et al (2011) Binding of blood proteins to carbon nanotubes reduces cytotoxicity. Proc Natl Acad Sci 108:1696816973. https://doi.org/10.1073/pnas.1105270108

Giau V-V, Park Y-H, Shim K-H et al (2019) Dynamic changes of protein corona compositions on the surface of zinc oxide nanoparticle in cell culture media. Front Chem Sci Eng 13:90-97. https://doi. org/10.1007/s11705-018-1766-Z

Godoy P, Hewitt NJ, Albrecht U et al (2013) Recent advances in 2D and $3 \mathrm{D}$ in vitro systems using primary hepatocytes, alternative hepatocyte sources and non-parenchymal liver cells and their use in investigating mechanisms of hepatotoxicity, cell signaling and ADME. Arch Toxicol 87:1315-1530. https://doi.org/10.1007/ s00204-013-1078-5

Gore E, Bigaeva E, Oldenburger A et al (2019) PI3K inhibition reduces murine and human liver fibrogenesis in precision-cut liver slices. Biochem Pharmacol 169:113633. https://doi.org/10.1016/j. bcp.2019.113633

Gubicza J, Lábár JL, Quynh LM et al (2013) Evolution of size and shape of gold nanoparticles during long-time aging. Mater Chem Phys 138:449-453. https://doi.org/10.1016/j.matchemphy s.2013.01.012

Guggenheim EJ, Milani S, Röttgermann PJF et al (2018) Refining in vitro models for nanomaterial exposure to cells and tissues. NanoImpact 10:121-142. https://doi.org/10.1016/j.impac t. 2018.02 .008

Gustafson HH, Holt-Casper D, Grainger DW, Ghandehari H (2015) Nanoparticle uptake: the phagocyte problem. Nano Today 10:487-510. https://doi.org/10.1016/j.nantod.2015.06.006

Hadjidemetriou M, Kostarelos K (2017) Evolution of the nanoparticle corona. Nat Nanotechnol 12:288

Holmes AM, Creton S, Chapman K (2010) Working in partnership to advance the 3 Rs in toxicity testing. Toxicology $267: 14-19$. https ://doi.org/10.1016/j.tox.2009.11.006

Hong J, Zhang Y-Q (2016) Murine liver damage caused by exposure to nano-titanium dioxide. Nanotechnology 27:112001. https://doi. org/10.1088/0957-4484/27/11/112001

Jasbi NE, Dorranian D (2016) Effect of aging on the properties of TiO2 nanoparticle. J Theor Appl Phys 10:157-161. https://doi. org/10.1007/s40094-016-0212-1

Kastl L, Sasse D, Wulf V et al (2013) Multiple internalization pathways of polyelectrolyte multilayer capsules into mammalian cells. ACS Nano 7:6605-6618. https://doi.org/10.1021/nn306032k

Kim JA, Åberg C, Salvati A, Dawson KA (2012) Role of cell cycle on the cellular uptake and dilution of nanoparticles in a cell population. Nat Nanotechnol 7:62-68. https://doi.org/10.1038/nnano 2011.191

Krewski D, Acosta D, Andersen M et al (2010) Toxicity testing in the 21st century: a vision and a strategy. J Toxicol Environ Health Part B 13:51-138. https://doi.org/10.1080/10937404.2010.483176

Krug HF (2014) Nanosafety research-are we on the right track? Angew Chem Int Ed. https://doi.org/10.1002/anie.201403367

Kuchibhatla SVNT, Karakoti AS, Baer DR et al (2012) Influence of aging and environment on nanoparticle chemistry: implication to confinement effects in nanoceria. J Phys Chem C 116:1410814114. https://doi.org/10.1021/jp300725s

Landsiedel R, Ma-Hock L, Wiench K et al (2017) Safety assessment of nanomaterials using an advanced decision-making framework, the DF4nanoGrouping. J Nanoparticle Res 19:171. https://doi. org/10.1007/s11051-017-3850-6

Lee I-C, Ko J-W, Park S-H et al (2018) Copper nanoparticles induce early fibrotic changes in the liver via TGF- $\beta$ /Smad signaling and cause immunosuppressive effects in rats. Nanotoxicology 12:637651. https://doi.org/10.1080/17435390.2018.1472313

Lesniak A, Fenaroli F, Monopoli MP et al (2012) Effects of the presence or absence of a protein corona on silica nanoparticle uptake and impact on cells. ACS Nano 6:5845-5857. https://doi. org/10.1021/nn300223w

Loos C, Syrovets T, Musyanovych A et al (2014) Functionalized polystyrene nanoparticles as a platform for studying bio-nano interactions. Beilstein J Nanotechnol 5:2403-2412. https://doi. org/10.3762/bjnano.5.250

Lu H, Dong H, Fan W et al (2017) Aging and behavior of functional $\mathrm{TiO} 2$ nanoparticles in aqueous environment. J Hazard Mater 325:113-119. https://doi.org/10.1016/j.jhazmat.2016.11.013

Lundqvist M, Stigler J, Cedervall T et al (2011) The evolution of the protein corona around nanoparticles: a test study. ACS Nano 5:7503-7509. https://doi.org/10.1021/nn202458g

Lunov O, Syrovets T, Loos C et al (2011) Amino-functionalized polystyrene nanoparticles activate the NLRP3 inflammasome in human macrophages. ACS Nano 5:9648-9657. https://doi. org/10.1021/nn203596e

Mahony C, Currie R, Daston G et al (2018) Highlight report: 'Big data in the 3R's: outlook and recommendations', a roundtable summary. Arch Toxicol 92:1015-1020. https://doi.org/10.1007/ s00204-017-2145-0

Materne E-M, Tonevitsky AG, Marx U (2013) Chip-based liver equivalents for toxicity testing — organotypicalness versus cost-efficient high throughput. Lab Chip 13:3481. https://doi.org/10.1039/c31c5 0240f

Monopoli MP, Åberg C, Salvati A, Dawson KA (2012) Biomolecular coronas provide the biological identity of nanosized materials. Nat Nanotechnol 7:779-786. https://doi.org/10.1038/nnano.2012.207

Nel A (2006) Toxic potential of materials at the nanolevel. Science 311:622-627. https://doi.org/10.1126/science.1114397

Ogawara K, Yoshida M, Higaki K et al (1999) Hepatic uptake of polystyrene microspheres in rats: effect of particle size on intrahepatic distribution. J Control Release 59:15-22

Olinga P, Schuppan D (2013) Precision-cut liver slices: a tool to model the liver ex vivo. J Hepatol 58:1252-1253. https://doi. org/10.1016/j.jhep.2013.01.009

Olinga P, Merema MT, de Jager MH et al (2001) Rat liver slices as a tool to study LPS-induced inflammatory response in the liver. J Hepatol 35:187-194. https://doi.org/10.1016/S0168 $-8278(01) 00103-9$

Park E-J, Park K (2009) Oxidative stress and pro-inflammatory responses induced by silica nanoparticles in vivo and in vitro. Toxicol Lett 184:18-25. https://doi.org/10.1016/j.toxle t.2008.10.012

Parrish AR, Gandolfi AJ, Brendel K (1995) Precision-cut tissue slices: applications in pharmacology and toxicology. Life Sci 57:18871901. https://doi.org/10.1016/0024-3205(95)02176-J

Pearson RM (1986) In-vitro techniques: can they replace animal testing? Hum Reprod Oxf Engl 1:559-560. https://doi.org/10.1093/ oxfordjournals.humrep.a136473

Pham BT, van Haaften WT, Oosterhuis D et al (2015) Precision-cut rat, mouse, and human intestinal slices as novel models for the early-onset of intestinal fibrosis. Physiol Rep 3:e12323. https:// doi.org/10.14814/phy2.12323

Poon W, Zhang Y-N, Ouyang B et al (2019) Elimination pathways of nanoparticles. ACS Nano 13:5785-5798. https://doi.org/10.1021/ acsnano.9b01383

Rim K-T, Song S-W, Kim H-Y (2013) Oxidative DNA damage from nanoparticle exposure and its application to workers' health: a literature review. Saf Health Work 4:177-186. https://doi. org/10.1016/j.shaw.2013.07.006

Sadauskas E, Wallin H, Stoltenberg M et al (2007) Kupffer cells are central in the removal of nanoparticles from the organism. Part Fibre Toxicol 4:10. https://doi.org/10.1186/1743-8977-4-10

Singh AV, Laux P, Luch A et al (2019) Review of emerging concepts in nanotoxicology: opportunities and challenges for safer 
nanomaterial design. Toxicol Mech Methods 29:378-387. https ://doi.org/10.1080/15376516.2019.1566425

Soldatow VY, LeCluyse EL, Griffith LG, Rusyn I (2013) In vitro models for liver toxicity testing. Toxicol Res 2:23-39. https:// doi.org/10.1039/C2TX20051A

Starokozhko V, Groothuis GMM (2017) Judging the value of 'liveron-a-chip' devices for prediction of toxicity. Expert Opin Drug Metab Toxicol 13:125-128. https://doi.org/10.1080/17425 255.2017.1246537

Starokozhko V, Groothuis GMM (2018) Challenges on the road to a multicellular bioartificial liver: bioartificial liver. J Tissue Eng Regen Med 12:e227-e236. https://doi.org/10.1002/term.2385

Starokozhko V, Abza GB, Maessen HC et al (2015) Viability, function and morphological integrity of precision-cut liver slices during prolonged incubation: effects of culture medium. Toxicol In Vitro 30:288-299. https://doi.org/10.1016/j.tiv.2015.10.008

Starokozhko V, Vatakuti S, Schievink B et al (2017) Maintenance of drug metabolism and transport functions in human precision-cut liver slices during prolonged incubation for 5 days. Arch Toxicol 91:2079-2092. https://doi.org/10.1007/s00204-016-1865-x

Suker DK, Jasim FA (2018) Liver histopathological alteration after repeated intra-tracheal instillation of titanium dioxide in male rats. Gastroenterol Hepatol Bed Bench 11:159-168

Thurnherr T, Brandenberger C, Fischer K et al (2011) A comparison of acute and long-term effects of industrial multiwalled carbon nanotubes on human lung and immune cells in vitro. Toxicol Lett 200:176-186. https://doi.org/10.1016/j.toxlet.2010.11.012

Tsoi KM, MacParland SA, Ma X-Z et al (2016) Mechanism of hardnanomaterial clearance by the liver. Nat Mater 15:1212-1221. https://doi.org/10.1038/nmat4718

Usta OB, McCarty WJ, Bale S et al (2015) Microengineered cell and tissue systems for drug screening and toxicology applications: evolution of in-vitro liver technologies. Technology 03:1-26. https ://doi.org/10.1142/S2339547815300012

Valentini X, Rugira P, Frau A et al (2019) Hepatic and renal toxicity induced by $\mathrm{TiO}_{2}$ nanoparticles in rats: a morphological and metabonomic study. J Toxicol 2019:1-19. https://doi. org/10.1155/2019/5767012

Wang F, Bexiga MG, Anguissola S et al (2013a) Time resolved study of cell death mechanisms induced by amine-modified polystyrene nanoparticles. Nanoscale 5:10868. https://doi.org/10.1039/c3nr0 $3249 \mathrm{c}$

Wang F, Yu L, Monopoli MP et al (2013b) The biomolecular corona is retained during nanoparticle uptake and protects the cells from the damage induced by cationic nanoparticles until degraded in the lysosomes. Nanomed Nanotechnol Biol Med 9:1159-1168. https://doi.org/10.1016/j.nano.2013.04.010

Westra IM, Pham BT, Groothuis GMM, Olinga P (2013) Evaluation of fibrosis in precision-cut tissue slices. Xenobiotica 43:98-112. https://doi.org/10.3109/00498254.2012.723151

Westra IM, Oosterhuis D, Groothuis GMM, Olinga P (2014a) The effect of antifibrotic drugs in rat precision-cut fibrotic liver slices. PLoS ONE 9:e95462. https://doi.org/10.1371/journal.pone.00954 62

Westra IM, Oosterhuis D, Groothuis GMM, Olinga P (2014b) Precision-cut liver slices as a model for the early onset of liver fibrosis to test antifibrotic drugs. Toxicol Appl Pharmacol 274:328-338. https://doi.org/10.1016/j.taap.2013.11.017

Westra IM, Mutsaers HAM, Luangmonkong T et al (2016) Human precision-cut liver slices as a model to test antifibrotic drugs in the early onset of liver fibrosis. Toxicol In Vitro 35:77-85. https ://doi.org/10.1016/j.tiv.2016.05.012

Wick P, Chortarea S, Guenat OT et al (2015) In vitro-ex vivo model systems for nanosafety assessment. Eur J Nanomed. https://doi. org/10.1515/ejnm-2014-0049

Xia T, Kovochich M, Liong M et al (2008) Cationic polystyrene nanosphere toxicity depends on cell-specific endocytic and mitochondrial injury pathways. ACS Nano 2:85-96. https://doi. org/10.1021/nn700256c

Xie G, Sun J, Zhong G et al (2010) Biodistribution and toxicity of intravenously administered silica nanoparticles in mice. Arch Toxicol 84:183-190. https://doi.org/10.1007/s00204-009-0488-x

Yu Y, Duan J, Li Y et al (2017) Silica nanoparticles induce liver fibrosis via TGF-\&beta; 1 /Smad3 pathway in ICR mice. Int J Nanomed 12:6045-6057. https://doi.org/10.2147/IJN.S132304

Zeisberg M, Kalluri R (2013) Cellular mechanisms of tissue fibrosis. 1. Common and organ-specific mechanisms associated with tissue fibrosis. Am J Physiol-Cell Physiol 304:C216-C225. https://doi. org/10.1152/ajpcell.00328.2012

Zhang Y-N, Poon W, Tavares AJ et al (2016) Nanoparticle-liver interactions: cellular uptake and hepatobiliary elimination. J Control Release 240:332-348. https://doi.org/10.1016/j.jconr el.2016.01.020

Publisher's Note Springer Nature remains neutral with regard to jurisdictional claims in published maps and institutional affiliations. 